\title{
واقع سلوك المواطنة التنظيمية وعلاقته بالصـورة الذهنية للجامعات السودانية \\ بالتطبيق على جامعة أم درمان الإسلامية (مجمع الطالبات)
}

\section{The Reality of Organizational Citizenship Behavior and its relationship to Mental Image of Sudanese Universities Applied to Omdurman Islamic University (Female Students \\ Complex)}

الاكتورة/ حنان عثمان عمسيب محمد

أستاذ إدارة الأعمال المساعد، كلية العلوم الإدارية، جامعة أم درمان الإسلامية، جمهورية السودان

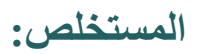

هدفت هذه الدر اسة إلى الكثف عن و اقع ممارسة سلوك المواطنة التنظيمية وعلاقته بالصورة الذهنية للجامعات السودانية من وجهة نظر عضوات هيئة التدريس و الموظفات بجامعة أم درمان الإسلامية (مجمع الطالبات)، وذلك من خلال اختبار ثناث فرضيات منمثلة في: توجد علاقة ذات دلالة إحصائية عند مستوى معنوية ج 0.05 بين سلوك المواطنة التنظيمية بأبعاده المختلفة (الإيثار ، الكياسة، الروح الرياضية، السلوك الحضاري، وعي الضمير) والصورة الذهنية. توجد فروق ذات دلالة إحصائية عند مستوى معنوية > 0.05 بين آراء عضوات هيئة التدريس والموظفات بجامعة أم درمان الإسلامية نحو سلوك المو اطنة التنظيمية تعزى لمتغيرات (الوظيفة، ومدة الخدمة، و المؤهل العلمي). توجد فروق ذات دلالة إحصائية عند مستوى معنوية > 0.05 بين آراء عضوات هيئة التدريس و الموظفات بجامعة أم درمان الإسلامية نحو الصورة الذهنية تعزى لمتغير ات (الوظيفة، ومدة الخدمة، والمؤهل العلمي). تمّ استخدام المنهج التاريخي لجمع البيانات الخاصة بالجزء النظري و الدراسات السابقة، وكذللك المنهج الوصفي التحليلي. كما نَّ استخدام الاستبيان لجمع البيانات من مجتمع الدراسة البالغ 1116 (571 عضوة هيئة تدريس، و545 موظفة)، باختبار عينة عشوائية طبقية بنسبة 10\% لكل منهما بلغت 112 (57 عضوة هيئة

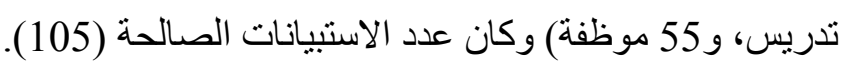

أُستخدم برنامج (SPSS) لتحليل البيانات واختبار الفرضيات باستخدام معامل ارتباط بيرسون، وتحليل التباين الأحسادي، توصلت الدر اسـة إلى عدة نتائج أهمها: وجود علاقة ذات دلالة إحصـائية عند مستوى معنويـة ج 0.05 بين سلوك المواطنـة التنظيمية بأبعـاده المختلفة، و الصـورة الذهنيـة. عدم وجود فروق ذات دلالـة إحصـائية عند مسنتوى معنويـة جـ 0.05 ببين آراء عضو ات هيئة التدريس و الموظفات بجامعة أم درمان الإسلامية نحو سلوك المواطنة التنظيمية تعزى لمتغير ات (الوظيفة، ومدة الخدمة، والمؤهل العلمي). عدم وجود فروق ذات دلالة إحصائية عند مستوى معنوية ج 0.05 بين آر اء عضوات هيئة التدريس و الموظفات بجامعة أم درمـان الإسـلامية نحو الصورة الذهنية قد تعزى لمتغيري (الوظبفة، ومدة الخدمـة) بينمـا توجد فروق تعزى لمتغير (المؤهل العلمي)، كما خرجت الدراسة بعدد من التوصيات. الكلمات المفتاحية: سلوك المواطنة التنظيمية، الصورة الذهنية، الإيثار، الكياسة، الروح الرياضية، وعي الضمير. 


\section{The Reality of Organizational Citizenship Behavior and its relationship to Mental Image of Sudanese Universities Applied to Omdurman Islamic University (Female Students Complex)}

\section{Abstract:}

This study aimed to reveal the reality of the practice of organizational citizenship behavior and its relationship to the mental image of Sudanese universities from the viewpoint of female teaching staff and female employees at the Islamic University of Omdurman (Female Students Complex), through testing three hypotheses represented in: There is a statistically significant relationship at a significant level $\leq 0.05$ between the behavior of organizational citizenship in its various dimensions (altruism, courtesy, Sportsmanship, cultural behavior, conscientiousness) and mental image. There is statistically significant differences at the level of significance $\leq 0.05$ between the opinions of teaching staff and employees at Omdurman Islamic University towards the behavior of organizational citizenship refer to variables (job, duration of service, and educational qualification). There is statistically significant differences at the level of significance $\leq 0.05$ between the opinions of teaching staff and employees at Omdurman Islamic University towards the mental image refer to the variables (job, duration of service, and educational qualification). The historical method was used to collect data for the theoretical part and previous studies, also the descriptive analytical method. The questionnaire was also used to collect data from the study population of 1116 (571 teaching staff and 545 employees), by selecting a stratified random sample with a rate of $10 \%$ for each of them amounting to 112 (57 teaching staff and 55 employees) and the number of valid questionnaires (105). SPSS program was used for data analysis and hypothesis testing, using the " Pearson correlation coefficient", and " One way ANOVA ". The study reached several results, the most important of which are: There is a statistically significant relationship at the level of significance $\leq 0.05$ between organizational citizenship behavior with its various dimensions and mental image. There aren't statistically significant differences at the level of significance $\leq 0.05$ between the views of female teaching staff and employees towards organizational citizenship behavior due to variables (job, duration of service, and educational qualification). 
There aren't statistically significant differences at the level of significance $\leq 0.05$ between the views of teaching staff and employees towards the mental image may be return to the two variables (job, and duration of service) while there are differences return to the variable (academic qualification), as the study came out with a number of recommendations.

Keywords: Organizational citizenship behavior, mental image, Altruism, civility, sportsmanship, conscientiousness

يُعد سلوك المواطنة التنظيمية واحداً من المفاهيم الإدارية المعاصرة التي استحوذت على اهتمام الكثير من الباحثين و العاملين في حقل الإدارة، وذلك لارتباطه بأهم مورد من موارد المؤسسة والمتمثل في الكادر البشري الذي لا يمكن لأي

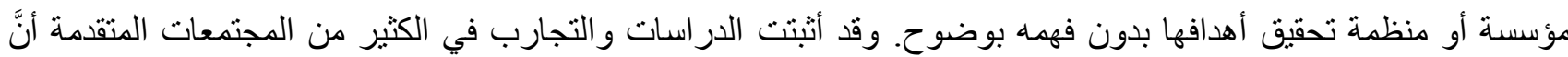
القوى البشرية المؤهلة وطريقة سلوكها في بيئة العمل هي أداة الإبداع الرئيسة وهي أيضاً أداة المنافسة الإيجابية. وهذا السلوك هوك يقصد به ما تعدى السلوك الرسهي إلى الاهتمام بالتفاعل الإيجابي غير الرسمي بين العاملين وهو ما بسمى " سلوك المواطنة التنظيمية". وبما أنَّه يتجاوز ما تفرضه عقود العمل وقوائم الوصف الوظيفي إلى الكثير من السلوكيات الطوعية الإيجابية فإنَّ ذللك قد يكون له أثرٌ إيجابي على العلاقات الداخلية بظهر جلياً في تمكين العاملين وإعطائهم الحرية والتصرف مما أدى إلى مئى الإبداع والابتكار ، وذلك بدوره ينعكس على المخرجات الكلية ويساهم في رفع و الارتقاء بكفاءة المنظمة وفعاليتها.

إنَّ الصورة الذهنية تعني الانطباع الذي يُكونه المجتمع عن المؤسسة المعينة، وهو مرتبط بالمشاعر، وقد يكون هذا

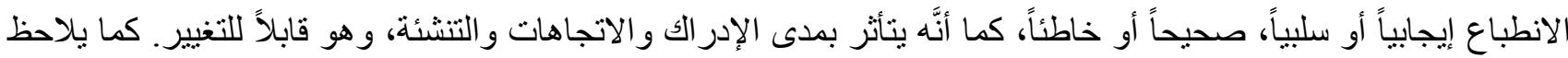
أنَّ المنظمات و المؤسسات تنفق الكثبر من الأموال لبناء الصورة الذهنية، مما يعني أنَّ الصورة الذهنية أصبحت من أهم عوامل النجاح التنظيمي لأنَّها تعمل على رفع الروح المعنوية للعاملين مما يؤدي إلى رفع قدر اتهم الإنتاجية، وينعكس فيما يقدمونه من منتجات سو اء كانت (سلع أو خدمات)، وبالتالي يساهم في رفع ثقة الجمهور الخارجي من العملاء و المستفيدين.

تُعتبر المؤسسات الجامعية من المؤسسات التي تقدم خدمات كبيرة للمتمع سواء في جانب البحث العلمي أو تتمية المجتمع، ولكي تضمن بقاءها فلا بد من رفع أدائها وتحسينه باستمر ار. مما جعلها تهنم بتتكيل صورة ذهنية حسنة لدى جمهور ها الداخلي من الطلاب و الأكاديميين و العاملين، وكذلك جمهورها الخارجي المتمثل في المؤسسات العلمية الأخرى و المجتمع. و أصبحت الصورة الذهنية من الفعاليات المهمة لها إذ لم يعد كافياً أن تُعنى بها إدارة العلاقات العامة فقط، بل يتطلب ذلك تضافر وتكامل جهود جميع الإدارات مما جعل عملية بناء وتطوير الصورة الذهنية الحسنة ذات أهمية استراتيجية، وأصبحت الصورة الذهنية للجامعة تمثل إحدى مكونات رأس المال الفكري والمتمثل فيما يُسمى رأس مال العلاقات (أي العلاقات مع الجمهور الداخلي والخارجي). و عليه يمكن القول إنَّ بناء صورة ذهنية مميزة أصبح غاية رئيسة لكل مؤسسة، لاسيما المؤسسات التعليمية التي إذا أر ادت أن تكون مستوفية لثروط المواطنة الصالحة وتتمكن من البقاء و الاستمر ارية، عليها أنْ تهنم بسلوك المو اطنة التنظيمية باعتباره ركناً رئيساً لبناء الصورة الذهنية الممتازة و المميزة لها. 
المجلة الدولية لنشر البحوث والدراسات

International Journal of Research and Studies Publishing
المجلد الثالث - الإصدار الثامن والعشرون تأريخ الإصدار: 20 فبراير 2022 م

مشكلة الاراسة وتساؤلاتها:

بما أنّ الجامعات هي مستودع المعرفة فإنَّ إقبال الطلاب عليها قد يكون أحد العوامل المميزة لها كمؤسسات ناجحة، وقد لاحظت الباحثة أنَّ أعداد القبول للالتحاق بجامعة أم درمان الإسلامية في السنوات الأخبرة من القرن الحالي قد نز ايد خاصة من جانب الطالبات في الكليات المختلفة، مما أدى إلى تساؤل الباحثة لمعرفة الأسباب المؤدية لذلك حيث بلغ عدد الطالبات في العام الدر اسي 2020/2019م ما يزيد على (26000 طالبة)، (علي محمد،2019م) علماً بأنَّ هناك شطر للطلاب قد يناظر ذلك العدد أو يقل، وقد يدل ذلك على ميزة تنافسية للجامعة تميزها عن غيرها من الجامعات. وبما أنَّ سلوكيات المواطنة التنظيمية للعاملين لها دور كبير في تحقيق النجاح التنظيمي و الذي يؤدي بدوره إلى تحقيق الميزة التنافسية، كما قد يكون له دورٌ كبيرٌ في هي رسم وترسيخ صورة ذهنية حسنة عن الجامعة فقد جاءت تساؤلات الدر اسة على النحو التالي: 1- ما هو مستوى توفر كل بعد من أبعاد سلوك المواطنة التنظيمية المختلفة لاى عضوات هيئة التدريس والموظفات بمجمع الطالبات بالجامعة محل الدر اسة ؟

2- ما هي تصور ات و آراء عضوات هيئة التدريس والموظفات بمجمع الطالبات عن الصورة الذهنية للجامعة؟ 3- هل توجد علاقة بين سلوك المواطنة التنظيمية لاى عضوات هيئة التدريس و الموظفات بمجمع الطالبات وتحسين الصورة الذهنية للجامعة؟ - الج

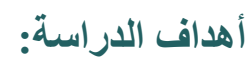
تسعى الدر اسة إلى تحقيق الأهداف التالية:1- تسليط الضوء على مفهومي سلوك المو اطنة التنظيمية والصورة الذهنية للمؤسسات التعليمية من خلال تناولهما من الناحية النظرية بغرض نشر المعرفة العلمية في وسط الباحثين و الأكاديميين. 2- محاولة معرفة الصورة الذهنية لدى عضوات هيئة التدريس و الموظفات بمجمع الطالبات عن الجامعة. 3- معرفة علاقة الارتباط بين سلوكيات المواطنة التنظيمية لدى عضوات هيئة التدريس و الموظفات بمجمع الطالبات والصورة الذهنية للجامعة.

4- تقديم توصيات تفيد متخذي القرار في دعم سلوكيات المواطنة التنظيمية لدى عضوات هيئة التدريس والموظفات بمجمع الطالبات بالجامعة للاستفادة منها في التحسين المستمر للصورة الذهنية للجامعة لدى جمهور ها الخارجي. أهمية الار اسة: الأهمية العلمية:- نظر اً لقلة البحوث و الدر اسات التي تناولت الربط بين متغيري هذه الدراسة في المكتبات السودانية على وجه الخصوص على حد علم الباحثة فإنَّ أهميتها تكمن في أنَّها قد تكون إضافة علمية للمكتبة السودانية في هذا المجال، وكذلك إفادة

الباحثين و الدارسين. 
المجلة الدولية لنشر البحوث والدراسات

International Journal of Research and Studies Publishing
المجلد الثالث - الإصدار الثامن والعشرون تأريخ الإصدار: 20 فبراير 2022 م

ISSN: 2709-7064

الأهمية العملية:- تأمل الباحثة أن نساعد نتائج ومخرجات هذه الدراسة في إفادة المسئولين ومتخذي القرار في معرفة الدور الكبير الذي تلعبه سلوكيات المواطنة التنظيمية للعاملين - إن تم الاهتمام بها وتشجيعها - في تشكيل الصورة الذهنية الحسنة و المميزة للمؤسسات عامة و المؤسسات التعليمية خاصة.

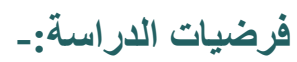

من خلال المشكلة والأهداف تعمل الدر اسة على اختبار الفرضيات التالية:-

الفرضية الأولى:- توجد علاقة ذات دلالة إحصائية عند مستوى معنوية ج 0.05 بين سلوك المواطنة التنظيمية لعضوات هيئة التدريس و الموظفات بجامعة أم درمان الإسلامية وتحسين الصورة الذهنية للجامعة. وتفر عت منها الفرضيات التالية:-



أم درمان الإسلامية وتحسين الصورة الذهنية للجامعة.

2- نوجد علاقة ذات دلالة إحصائية عند مستوى معنوية ج205 بين الكياسة لدى عضوات هيئة التدريس والموظفات بجامعة أم درمان الإسلامية وتحسين الصورة الذهنية للجامعة. 3- نوجد علاقة ذات دلالة إحصائية عند مسنوى معنوية 20.05 بين الروح الرياضية لدى عضو ات هيئة التدريس و الموظفات بجامعة أم درمان الإسلامية وتحسين الصورة الذهنية للجامعة.


و الموظفات بجامعة أم درمان الإسلامية وتحسين الصورة الذهنية للجامعة.

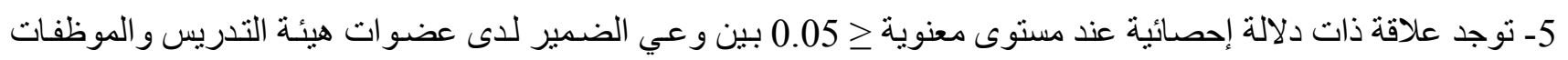
بجامعة أم درمان الإسلامية وتحسين الصورة الذهنية للجامعة.

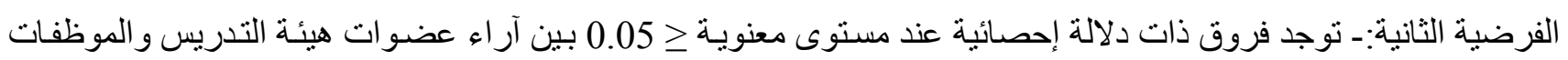
بجامعة أم درمان الإسلامية نحو سلوك المو اطنة التنظيمبة تعزى لمتغير ات (الوظيفة، ومدة الخدمة، والمؤهل العلمي). الفرضية الثالثة:- توجد فروق ذات دلالة إحصائية عند مستوى معنوية ج 0.05 بين آراء عضوات هيئة التدريس و الموظفات بجامعة أم درمان الإسلامية نحو الصورة الذهنية تعزى لمتغيرات (الوظيفة، ومدة الخدمة، و المؤهل العلمي). نموذج الدراسة:- تم وضع نموذج الدراسة ليوضح المتغير المستقل والمتمثل في (سلوك المواطنة التنظيمية)، والمتغير التابع المتمثل في (الصورة الذهنية )، وذلك في الثكل (1) 


\section{شكل (1): أنموذج الدراسة}
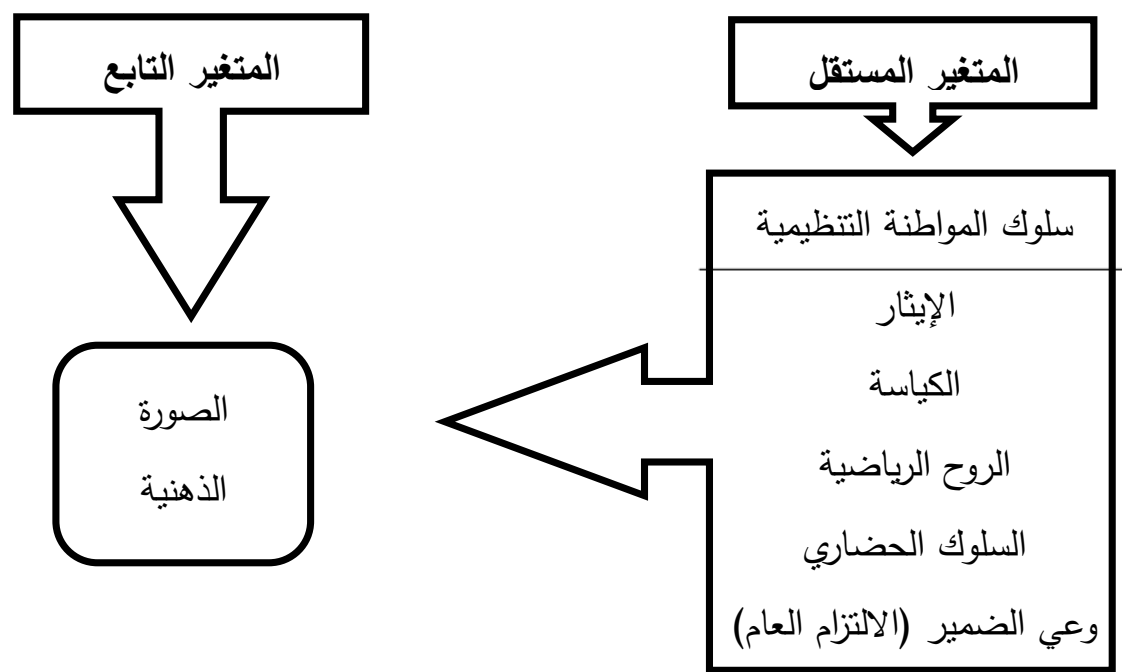

المصدر: إعداد الباحتَّة، من خلال فرضيات الدراسة، 2020م

مصطلحات الار اسةة:-

سلوك المواطنة التنظيمية:- " أعمال وأدوار تطوعية واختيارية تتجاوز نظام المكافآت والحوافز الرسمية، ويمارسها الموظفون بهدف إنباع حاجاتهم ولمساعدة الآخرين وتعود بالفائدة على المنظمة ككل، وتسهم في زيادة تماسك المنظمة وتحقيق

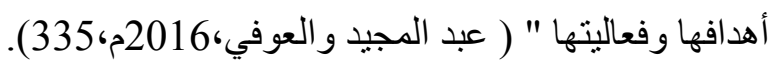

الصورة الذهنية: " هي التصور العقلي الذي يتكون في أذهان الناس عن الثركات والمؤسسات المختلفة، والنابعة إما عن التجربة المباثرة أو غير المباشرة، وقد تكون عقلانية أو غير عقلانية، وقد تعتمد على الأدلة والوثائق، أو على الإشاعات و الأقوال غير الموثوقة، ولكنها في النهاية تمثل واقعاً بالنسبة لمن يحملونها في أذهانهم عن الخدمات أو المنتجات المقدمة لهم "

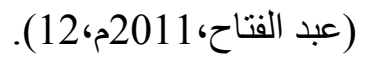

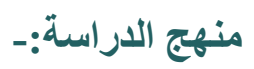
تنَّ استخدام المنهج التاريخي لسرد الجانب النظري، وكذلك منهج دراسة الحالة ل وصف الظاهرة من خلال منهج المسح الاجتماعي، بالإضافة إلى المنهج الوصفي التحليلي لاختبار فرضيات الدراسة. مصادر وأدوات جمع البيانات:-

أستخدم الباحث المصادر الثانوية للحصول على الجانب النظري، وذلك من خلال الكتب و المجلات العلمية والرسائل العلمية و الانترنت، كما تم استخدام المصادر الأولية متمثلة في الاستبيان لجمع البيانات من مجتمع الدر اسة. 


$$
\text { حدود ومجالات الدراسة:-- }
$$

المجال المكاني: جامعة أم درمان الإسلامية (مجمع الطالبات).

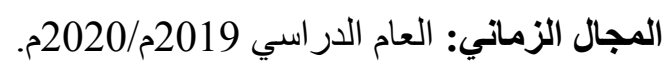

المجال البشري: عضوات هيئة التدريس والموظفات بجامعة أم درمان الإسلامية (مجمع الطالبات).

المجال الموضوعي: الربط بين سلوكيات المواطنة التنظيمية لاى عضوات هيئة التدريس و الموظفات بمجمع الطالبات بالجامعة

للاستفادة منها في التحسين المستمر للصورة الذهنية للجامعة.

$$
\text { هيكل الاراسة:-- n }
$$

تتكون الدر اسة من مقدمة وثلاثة مباحث وخاتمة.

تشتمل المقدمة على مشكلة الدراسة وتساؤلاتها، أهداف الدراسة، أهمية الدراسة، فرضيات الدراسة، نموذج الدراسة، مصطلحات الدر اسة، منهج الدراسة، حدود ومجالات الدراسة، و هيكل الدر اسة.

يتناول المبحث الأول الإطار النظري للار اسة منمثلاً في سلوك المواطنة التنظيمية من حيث مفهومه وأهميته، خصائصه، أنو اعه و أنماطه، أبعاده، ومحدداته. وكذلك الصورة الذهنية من حيث مفهومها وأهميتها، خصائصها وسماتها، أنو اعها، أبعادها و العو امل المؤثرة في تشكيلها، وخطوات تحسينها. بالإضافة إلى الدراسات السابقة المتعلقة بمتغيري الدراسة (سلوك المواطنة

التنظيمية والصورة الذهنية).

بينما يحتوي المبحث الثاني على الإطار التطبيقي مشتملاً على إجر اءات الدراسة الميدانية، وعرض وتحليل البيانات ونتائج واختبار الفرضيات.

أما الخاتمة تتضمن خلاصة النتائج و التوصيات.

المبحث الأول: الإطار النظري والدراسات السابقة

Organizational citizenship behavior أولاً- سلوك المواطنة التنظيمية ولإنة

1- مفهوم سلوك المواطنة التنظيمية وأهميته:-

Informal ( في ثلاثينيات القرن الماضي وفي العام 1938م ظهر في علم الإدارة ما يسمى بالتنظيم غير الرسمي و هذا المفهوم جاء ليؤكد على ضرورة التعاون بين أعضاء المنظمة لتحقيق مصالح و أهداف المنظمة. وقد كان نقطة البداية للاهتمام بالسلوك غير الرسمي للعاملين، ثم نوالت الدراسات والبحوث التي اهتمت بالسلوكيات التطوعية، و التي بدور ها أنتجت تطور ات كثيرة في علم الإدارة حتى ظهر ما يسمى (سلوك المو اطنة التنظيمية) وذللك في نهاية السبعينات وبداية الثمانينات من القرن الماضي على يد العالم (Dennis W. Organ) الذي يعتبر الأب الر اعي لهذا المفهوم، حيث كانت الدر اسة التي أجر اها بصدد تفسير العلاقة بين الرضاء والإنتاجية هي الأساس لاهتمام الباحثين من بعده بالسلوكيات التطوعية. 
وبالتالي أصبح هذا المفهوم أحد أهم المجالات في علم السلوك التنظيمي (ظاظا، 2017م، 26). إلا أنَّ هنالك من يرى أنَّ أول من أشتار لهذا المصطلح هو العالم (كاتز - Katz) ( دعنا،2017م،20). كما أنَّ هذا المسمى قد سبقته عدة تسميات منها سلوك

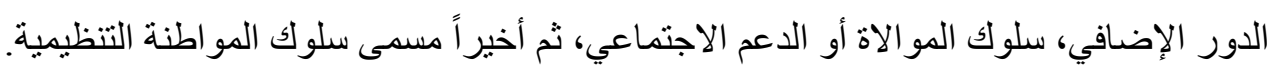

عُرِّف سلوك المو اطنة التنظيمية بأنَّه: " السلوك التقديري الزائد عن الدور الرسمي للفرد، و الذي يساعد على تحقيق الفعالية التنظيمية" (ظاظا، 2017م، 26).

كما عُرِّفِ بأنَّه: " عبارة عن مجموعة من السلوكيات الطوعية التي لا تشكل جزءاً رسمياً من مهام الموظف، لكنها يمكن أن

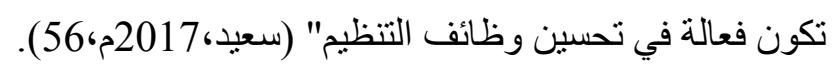

أيضاً هناك من عرَّفه بأنَّه: " التصرفات الإيجابية الزائدة عما هو موصوف رسمياً في المنظمة، والتي تمتاز بالطبيعة الاختيارية غير الإكر اهية، وغير الخاضعة للمكافأة مباشرة وصراحة في نظام الحوافز الإداري للمنظمة، وهي ذات أهمية

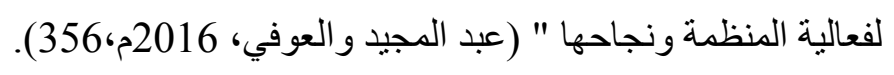

إنَّ هذه المفاهيم تشير وتؤكد على أهمية سلوك المواطنة التنظيمية الذي أصبح مطلباً للكثير من منظمات اليوم التي تعمل على تحسين أدائها، وزيادة فعاليتها. وذلك لأنَّه يحقق فوائد كثيرة للمنظمة والعاملين معاً من خلال تحسين الأداء الفردي و المؤسسي، إدارة الوقت بشكلٍ فعال، تحسين العمليات التنظيمية وتنمية الإبداع والابتكار، بالإضافة إلى تعزيز بقاء المنظمة ولهاء وقدرتها على المنافسة وحمايتها من الأخطار. وعليه يمكن ذكر عدد من النقاط التي نوضح أهمية هذا السلوك فيما يلي( المصري،2015م،23):

أـ خلق الحماس في الأداء بالنسبة للعاملين بعكس العمل الروتيني. بـ إتاحة الفرصة لممارسة الديمقر اطية من حيث اختيار نوع الأداء، والوقت الذي يناسب الموظف. ج- توطيد العلاقات بين الأفر اد و الجماعات، مما ينعكس إيجاباً على الأداء. د- زيادة كفاءة وفاعلية الموظف في العمل.

2- خصائص سلوك المواطنة التنظيمية:-

من المفاهيم السابقة لسلوك المواطنة التنظيمية بمكن استنباط العديد من الخصائص و السمات والتي يمكن تلخيصها في



أـ أنَّه سلوك مرتبط بالأدوار الإضافية التي تتعدى حدود الواجبات الوظيفية الأساسية. بـ أنَّهَ سلوك تطو عي واختياري غير ملزم للفرد، لأنَّه لم يُنص عليه ضمن الوصف الوظيفي الرسمي. ج- أنَّه سلوك ينوقع أنْ يؤخذ في الاعتبار عند ظهور فرصة تتافسية في المنظمة. 
المجلة الدولية لنشر البحوث والدراسات

International Journal of Research and Studies Publishing
المجلد الثالث - الإصدار الثامن والعشرون تأريخ الإصدار: 20 فبراير 2022 م

دـ أنَّهَ سلوك ينعكس إيجاباً على تتمية فعالية المنظمة و الارتقاء بالأداء الكلي لها. هـ أنَّهُ سلوك ينتج عن مجمو عة من الأفعال وليس فعلاً واحداً، ويختلف من منظمة إلى أخرى.

3- أنواع سلوك المواطنة التنظيمية وأنماطه:-

يُلاحظ من الخصائص المذكورة سابقاً أنَّ هناك أنواع لسلوك المو اطنة التنظيمية، وكذلك سميت أنماط، أما بالنسبة لأنو اعه

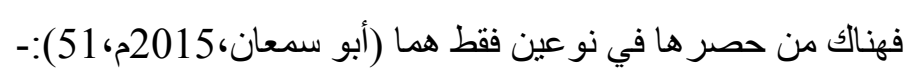

أـ سلوكيات إيجابية: و هي التي يمارسها الفرد العامل طو اعية مثل مساعدة الزملاء في العمل، وتقديم اقتر احات لتحسين صورة

المنظمة.

بـ- سلوكيات جودة الامتناع: وهي السلوكيات التي يمتنع عنها الفرد مثل عدم التعبير عن الاستياء من أوضاع العمل، وعدم إثارة المشاكل و الثكوى و التذمر.


أـ سلوك المواطنة الموجه نحو المنظمة: ويتضمن السلوكيات التي تعكس الالتزام والولاء للمنظمة، وتتشمل أيضاً الامنثال للقو اعد والسياسات و الإجر اءات المنصوص عليها. بـ سلوك المواطنة الموجه نحو الأفر اد العاملين بالمنظمة: ويتضمن السلوكيات التي تساعد وتدعم أفر اد المنظمة مثل مساعدة

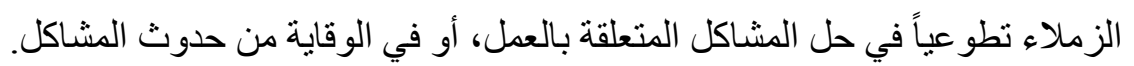
ج- سلوك المواطنة نحو الزبون.

أما من أطلق عليها أنماط فقد أجملها في عدد من السلوكيات منها (مناصرية وبن ختو، 2015م، 222-223):أـ مساعدة الزملاء فيما يتعلق بشئون العمل، وكذلك الثئون الثخصية. بـ مساعدة العملاء و المر اجعين في أمور لا تتعلق بالسلع و الخدمات المقدمة.

ج- اقتر اح تحسينات تنظيمية أو إدارية أو إجر ائية من أجل جعل المؤسسة أكثر نجاحاً. دـ تقديم المؤسسة للآخرين بصورة جيدة و الدفاع عنها بما يساهم في تحسين سمعتها عند الآخرين. 4- أبعاد سلوك المواطنة التنظيمية:-

يمكن تحديد أبعاد سلوك المواطنة التنظيمية في خمسة أبعاد هي (المصري،2015م، 25):-

أـ الإيثار Altruism: هو نمط من السلوك يقوم به الموظف لمساعدة الآخرين بشكل مباشر أو غير مباشر لحل مشكلاتهم

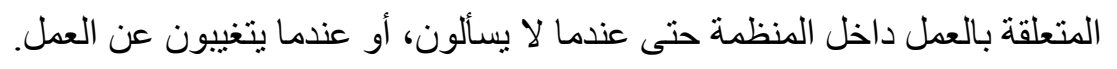


بـ الكياسة Courtesy: ويطلق عليه اللباقة واللطف والمجاملة وهو السلوك الذي يحرص فيه الموظف على منع وقوع المشكلات المتعلقة بالعمل، وتجنب استغلال الآخرين أو القيام بمشاكل معهر.

ج- وعي الضمير Conscientiousness: ويطلق عليه الضمير الحي والطاعة العامة، ويقصد به إخلاص الفرد لمثاليات يضعها كمعيار لسلوكه حيث يقوم بالعمل بجدية تامة، ويقدم المصلحة العامة على حساب مصلحته الثخصية.

دـ الروح الرياضية Sportsmanship: وهي رغبة العامل في التسامح، وقدرته على تحمل المشكلات والمهام الصعبة

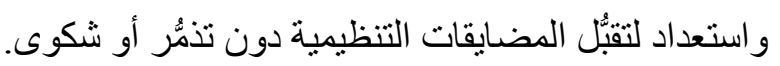

هـ السلوك الحضاري Civic Virtue: ويسمى فضيلة المواطنة هو إظهار سلوك الانتماء للمؤسسة والولاء لها وتحسين سمعتها و الدفاع عنها.

5- محددات سلوك المواطنة التنظيمية:-

حصرت هذه المحددات في مجموعة من المتغيرات منها متغيرات اتجاهات العاملين (مثل الرضاء والانتماء)، ومجموعة متغيرات بيئة العمل (مثل الدعم التنظيمي، النمط القيادي)، ومجموعة المتغيرات الثخصية (مثل القيم وأنماط السلوك)، ومجمو عة المتغير ات الديموغر افية (مثل السن، الخبرة، الحالة الاجتماعية) (نادر، 2012م، 80-81). وكل هذه تعتبر محددات ذات تأثثر على سلوك المواطنة التنظيمية والذي ينعكس على الفعالية التنظيمية.

Mental image ثانياً: الصورة الذهنية

1- 1 - مفهوم الصورة الاهنية وأهميتها:-

تعتبر الصورة الذهنية إحدى الموارد غير الملموسة التي تزيد من الميزة التنافسية المستدامة للمؤسسات، مما يجعلها سبباً في جذب والاحتفاظ بالكفاءات و أصحاب المقدرات العالية من الموظفين. وقد ظهر مصطلح الصورة الذهنية إلى الوجود في العام 1908م على يد العالم جراهام دالاس، وهذا المصطلح له علاقة بالمنشآت التجارية، وهو مشتق من الكلمة اللاتينية

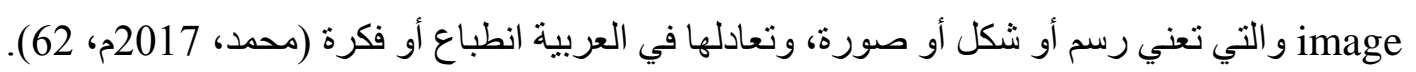
عُرِّفْت الصورة الذهنية بأنَّها: " مجموعة السمات و الملامح التي يدركها الجمهور ويبني على أساسها مو اقفه و اتجاهاته نحو المنظمة أو الجماعة، وتتكون هذه الصورة عن طريق الخبرة الثخصية للجمهور القائمة على الاتصال المباثر" (العادلي،2013م، 408).

كذلك عُرِّتْْ بأنَّها: " صورة شاملة يتم تشكبلها بواسطة المتغيرات مثل المنتجات الفريدة والاقتصادية والسياسية، والتنمية والأحداث التاريخية، والعلامات ومستوى التصنيع، والتطور التكنولوجي، ويتم نقلها بواسطة أنواع الإعلام المختلفة" (العسيري، 2018م، 8) (1) (1) 
الهجلة الدولية لنشر البحوث والدراسات

International Journal of Research and Studies Publishing
المجلد الثالث - الإصدار الثامن والعشرون تأريخ الإصدار: 20 فبراير 2022 م

أما بالنسبة لأهمية الصورة الذهنية للمؤسسة فهي بشكلٍ عام نشكل عاملاً مهماً في تسويق أهداف المؤسسة في أداء

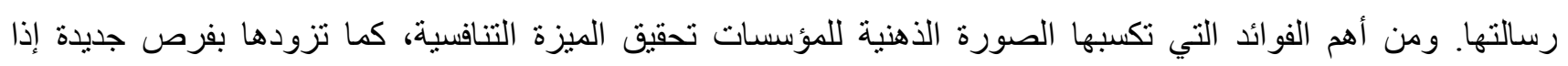
تعرضت لأزمة، وبالتالي تعتبر إحدى الأصول الاستر اتيجية التي تقود إلى بقاء المنظمة ونطور ها (عبد الخير وبدوي و عبد الله، (7، 7017

\section{2- خصائص وسمات الصورة الذهنية:-}

تتسم الصورة الذهنية بالعديد من الخصائص منها (زين العابدين،2019م،281):أـ لها إطار اً زمنياً سابقاً، بمعنى أنَّها قديمة. بـ لها إطار اً ذاتياً حسياً، أي تتبع من قدرة الفرد على استيعاب المثير. ج- تختلف من فرد لآخر. دـ تتسم بالعاطفة، بالر غم من أنَّ ذلك ليس مقياساً أساسياً في كل الأحو ال. هـ ديناميكية أي غير ثنابتة. وقد أضاف إليها (محمد،2017م،67) عدم الدقة، وتخطي حدود المكان، و التنبؤ بالمستقبل.

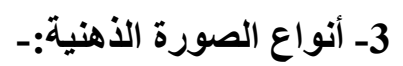
صنفت الصورة الذهنية إلى عدة أنو اع هي (معرب،،2015م،76):أـ الصورة المر آة: وهي التي ترى المؤسسة نفسها من خلالها. بـ الصورة الحالية ( المدركة): وهي التي برى بها الآخرون المؤسسة ج- الصورة المر غوبة: وهي التي ترغب المؤسسة أنْ تكونها في أذهان الجمهور. دـ الصورة المثلى: وهي الصورة التي يمكن أن تتحقق إذا أخذت المؤسسة في الاعتبار المنافسين وتأثير هم على الجمهور. هـ الصور المتعددة: و هي التي تكونها الانطباعات المحايدة فتكون الصورة إيجابية أحياناً، وتكون سلبية أحياناً أخرى. 4- أبعاد الصورة الذهنية والعوامل المؤثرة في تكوينها:تتمثل أبعاد الصورة الذهنية في (بن الثيخ، 2017م، 23):أـ البُعد المعرفي: وأساسه المعلومات و المعارف التي يحصل عليها الأفر اد. 
بـ البُعد الوجداني: ويقصد به الميل بالإيجاب أو السلب تجاه موضوع معين. ج- البُعد السلوكي: أي التنبؤ بسلوك الأفر اد، و الذي يعكس اتجاهاتهم.

إنَّ هذه الأبعاد مجتمعة تكوَّن الصورة الذهنية عن المؤسسة، بالإضافة إلى عوامل أخرى تساهم في تشكيلها مثل رؤية ورسالة المؤسسة وثقافتها، هوية المؤسسة (اسمها وشعارها)، تو اصل المؤسسة مع الجماهير، والمسئولية الاجتماعية (معمري،2015م،80). وكذللك أضيفت عو امل أخرى متعلقة بالزبون مثل الكلمة المنطوقة، الحاجات و التفضيلات الثخصية، وتجارب الزبون السابقة مع المؤسسة ( العسيري،2018م، 25). 5- خطوات تحسين الصورة الذهنية:للعمل على تحسين الصورة الذهنية للمؤسسة لا بد من إتباع بعض الخطوات مثل(باصرة،2004م):أـ التقييم الداخلي وتحديد الصورة الذهنية التي ترغب المؤسسة في تكوينها. بـ معرفة الصورة الذهنية الحالية التي يحملها الجمهور عن المؤسسة. ج- التصميم و التنفيذ لخطط العمل. دـ التسويق داخلياً وخار جياً للصورة الذهنية المستهدفة.


ثُالثا: الار اسات السابقة:-1- الدراسات المتعلقة بمحور سلوك المواطنة التظيمية:-

در اسة ( حسني، 2021م،977):- هدفت الدراسة إلى اختبار طبيعة العلاقات بين أبعاد الالتز ام التنظيمي كمتغير وسيط في العلاقة بين أبعاد الصمت التنظيمي كمتغير مستقل وأبعاد المواطنة التنظيمية كمتغير تابع، تم استخدام الاستبيان لجمع بيانات الدراسة التي بلغ عددها 372 استبيان ورقي و إلكتروني، وزعت على عينة عشوائية من العاملين بشركات قطاع

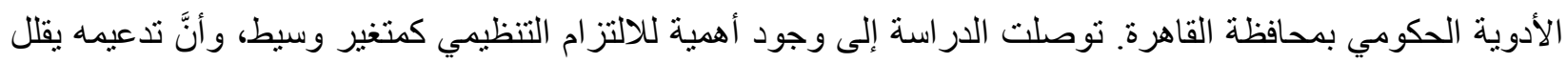

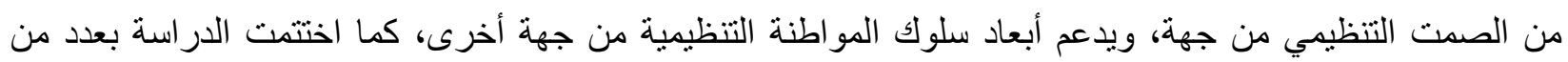
التوصيات.

در اسة (شهري 2019م،373):- عملت الدر اسة على الكثف عن مستوى أعضاء هيئة التدريس لسلوك المو اطنة التنظيمية في الجامعات الحكومية الجزائرية من وجهة نظر قادنها الأكاديمبين، اعتمدت الدراسة على المنهج الوصفي التحليلي نم توزيع استبيان لعينة عشو ائية بعدد (100) موظف ممن يشغلون مناصب قيادية في كلبة الاقتصاد و التجارة والتسبير

$$
\text { بجامعتي (بومرداس) و (الجزائر ). }
$$


أكدت نتائج الدراسة على وجود فروق ذات دلالة إحصائية عند مستوى الدلالة ج 0.05 في تقدير المبحوثين لمستوى ممارسة أعضاء هيئة التدريس لسلوك المواطنة التنظيمية تعزى فقط لمتغير المؤهل العلمي، كذلك توصلت إلى وجود مستويات متوسطة من ممارسة أعضاء هيئة التدريس لسلوك المواطنة التنظيمية من وجهة نظر القادة الأكاديميين. وخرجت الدر اسة بعدد من التوصيات.

در اسة (Chien,2019,1) ):- هدفت هذه الورقة إلى شرح كيفية تحسين سلوك المو اطنة التنظيمية ، وكذلك كيفية تطوير خطة للحصول على أو اكتساب سلوك مواطنة تنظيمية مستمر من خلال نظام رسمي، ووضع بيئي غير رسمي في مكان العمل. كما ركزت الورقة على وضع تحديد واضح للعلاقة بين الفعالية التنظيمية وسلوك المواطنة التنظيمية. كما قدمت مقترح تطبيقي كمحاولة للوصول إلى مخرجات تعمل على تحسين هذا السلوك. وقد أشنارت نتائج الدر اسة إلى وجود علاقة ارتباط بين كلٍ من (مناخ العمل الجيد (الإيجابي)، وموارد المنظمة، ومسئولية الموظفين، والثقافة التنظيمية، وغيرها) وسلوك المواطنة التنظيمية الذي يعتبر أفضل وسيلة لتحقيق الفعالية التنظيمية وبأقل تكلفة.

در اسة (عطية و المقدم،2018م،785):- هدفت الدراسة إلى اختبار الدور الوسيط للاتصال الفعال(للغة الدافعة) و التي يمكن أن يستخدمها القائد الخادم في التأثير على سلوكيات المواطنة التنظيمية للتابعين له، وقد نم جمع البيانات عن طريق الاسنبيان الذي وزع على عينة عشو ائية طبقية بلغت 550، نم استرداد 493 منها صالحة للتحليل، وقد تم تحليل البيانات التي جمعت باستخدام العامل التوكيدي و أسلوب نمذجة المعادلة البنائية، نوصلت النتائج إلى أنَّ تأثير القائد الخادم على التزام تابعيه،

وعلى سلوكيات المو اطنة التنظيمية لديهم يتوقف على استخدامه للغة الدافعة، كما خرجت الدراسة بعدد من التوصيات التطبيقية

در اسة (يغمور وسعيفان و عبداله،2018م،603):- هدفت هذه الدراسة إلى معرفة دور الأنماط القيادية الحديثة في تعزيز سلوك المواطنة التنظيمية لاى الموظفين العاملين في البنوك الأردنية، وقد نتَّ اختيار أربعة أنماط قيادية هي القيادة التحويلية، القيادة التبادلية، القيادة الأخلاقية، والقيادة الساكنة الانطوائية. أُستخدم الاستبيان لجمع البيانات من عينة عشو ائية بلغت 600 موظف، كانت الصالحة منها للتحليل 395. وقد أظهرت نتائج الدراسة أنَّ لأنماط القيادة التحويلية و التبادلية والأخلاقية أثراً إيجابياً على سلوك المواطنة التنظيمية للموظفين، بينما كان لنمط القيادة الساكنة أثرُ سلبي على سلوك المواطنة التنظيمية للموظفين. كما خرجت الدراسة بعدد من التوصيات.

دراسة (سعيد،2017م،7):- هدفت الدراسة إلى التعرُّف على مستوى الاغتراب الوظيفي، ومستوى سلوك المواطنة التنظيمية وتحديد طبيعة العلاقة بينهما، وكذلك معرفة الفروق بين متوسطات استجابات المبحوثين تبعاً للمتغير ات الديمو غر افية

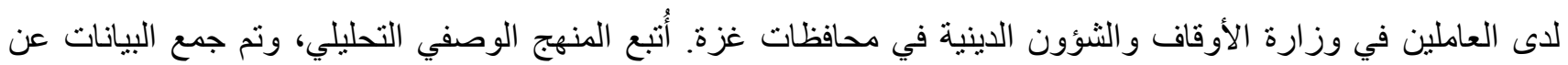
طريق الاستبيان الذي وزع على عينة عشوائية بسيطة بلغت 279. توصلت نتائج الدراسة إلى وجود علاقة عكسية ذات دلالة إحصائية بين الاغتر اب الوظيفي وسلوك المواطنة التنظيمية، كما خرجت بعدد من التوصيات. 
در اسة (Velicovska,2017,40):- تعتبر هذه الورقة در اسة استطلاعية لظاهرة سلوك المواطنة التنظيمية منذ ظهور هذا المصطلح في أدبيات الإدارة إلى العصر الحاضر، من حيث تعريفه والتغير ات التي طر أت عليه، هذا بجانب تحليل العلاقة بينه وبين بعض المفاهيم الأخرى القريبة منه و المرتبطة به مثل الثقافة التنظيمية، الاتجاهات، القيم و غير ها. ومن خلال التحليل تم اكتشاف أنَّ إمكانية إدارة هذا السلوك يعتمد على دور القائد باعتباره عامل محفّز لتعزيز سلوك المواطنة التنظيمية، هذا وقد

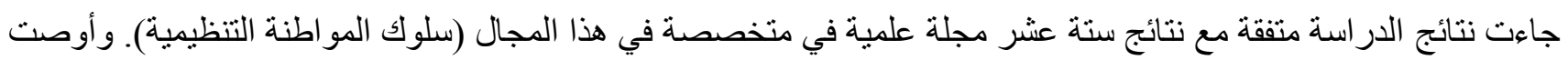
الدر اسة بإجر اء المزيد من الدراسات المستقبلية حول هذا المفهوم باعتباره جديداً بعض الثيء.

در اسة (سعدون وغيات وبز ايد،2017م، 182):- هدفت هذه الدراسة التعرُف على العلاقة بين سلوك المواطنة التنظيمية والإبداع الإداري، وأجريت على عينة من إطارات مؤسسة سوناطر الك فرع المصب بو هران، وذللك بالتطبيق على عينة عشوائية مكونة من 100 إطار، وبإتباع المنهج الوصفي التحليلي، وأسفرت نتائج الدراسة عن وجود علاقة ارتباط بين المو اطنة التنظيمية و الإبداع الإداري.

در اسة (رسول،2016م،176):- هدفت هذه الدر اسة إلى التعرُّف على مستوى سلوك المواطنة التنظيمية لدى أعضاء الهيئة التدريسية في كليات و أقسام التربية الرياضية في جامعات صلاح الدين وسو لان وكوية، تم استخدام المنهج الوصفي، وكذلك

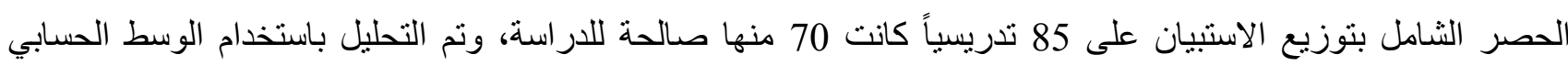
والانحر اف المعياري ومعامل الارتباط، وتحليل التباين. وتوصلت الدراسة إلى وجود فروق ذات دلالة معنوية في مستوى لإن سلوك المو اطنة التنظيمية لاى الكوادر التدريسية في محل الدراسة، كما خرجت بعدد من التوصيات.

دراسة) Hatami\& et al,2016,97 ):- إنَّ هدف هذه الدراسة هو التقدير والتنبؤ بسلوك المواطنة التنظيمية لدى الموظفين العاملين في وزارة الثباب والرياضة في الجزء الغربي من تركيا، وذللك بالاعتماد على عوامل الرضاء الوظيفي. وهي در اسة تطبيقية أجريت على عينة بلغت 164 من مجتمع الموظفين في كل إدارات الوزارة و البالغ عددهم 266 فرداً، نمَّم جمع البيانات عن طريق الاستبيان، كما أستخدم برنامج SPSS لتحليل البيانات، أظهرت نتائج الدراسة وجود علاقة ذات دلالة إحصائية بين الرضاء الوظيفي بكل أبعاده وسلوك المواطنة التنظيمية، كما أظهر اختبار المتغيرات المتوقعة أنَّ بُعد المناخ التنظيمي يمكن أن يكون له تفسير اً معنوياً للاختلاف في سلوكيات المو اطنة التنظيمية للموظفين.

دراسة ( المصري،2015م،7): هدفت هذه الدراسة إلى التعرُّ على العلاقة بين الانغماس الوظيفي وسلوك المواطنة التنظيمية لدى الأطباء العاملين في المستشفيات الحكومية بقطاع غزة، اعتمد الباحث على المنهج الوصفي، واستخدم الاستبيان لاسنطلاع رأي عينة عشوائية طبقية بلغت 285 طبيباً في 13 مسنتفى حكومي. أظهرت النتائج وجود علاقة طردية بين الانغماس الوظيفي بجميع أبعاده (انغماس عاطفي، معرفي، وسلوكي) مع سلوك المواطنة التنظيمية، كما أظهرت وجود فروق ذات دلالة إحصائية حول مستوى سلوك المو اطنة التنظيمية للأطباء العاملين في المستشفيات الحكومية وفقاً لمتغيري العمر، و اسم المستشفى، وكذلك وجود فروق ذات دلالة إحصائية حول الانغماس الوظيفي تبعاً لمتغيرات العمر، الجنس، المسىى الوظيفي، سنوات الخدمة، المؤهل العلمي، و اسم المستشفى. وقد خرجت الدر اسة بعدد من التوصيات من أهمها: تعظيم و غرس قيم سلوك المو اطنة التنظيمية و الانغماس الوظيفي عند الأطباء على اختلاف شخصياتهم. 
دراسة (Acaray\& Akturan,2015,472):- إنَّ هدف هذه الدراسة بحث تجريبي عن تأثير أبعاد الصمت التنظيمي على سلوك المو اطنة التنظيمية، تم جمع البيانات من عينة بلغت 462 موظفاً بالمركز الرئيس لإحدى الثركات الخاصة المتعددة الجنسية في استانبول وذلك عن طريق الاستبيان، وتم اختبار الفرضيات بواسطة تحليل الانحدار. وقد أوضحت النتائج وجود تأثير سلبي بين كلٍ من بُعدي الصمت الدفاعي، وصمت الاستسلام (الإذعان) وسلوك المواطنة التنظيمية، بينما يوجد تأثنير اجتماعي بين بُعد الصمت الاجتماعي وسلوك المواطنة التنظيمية.

2- 2 - الاراسات المتعلقة بمحور الصورة الذهنة:-

دراسة (أبو عجوة، 2021م،1):- هدفت إلى اختبار وتحليل علاقتي الارتباط والأثر بين أبعاد التسويق الفيروسي وتحسين الصورة الذهنية من وجهة نظر عملاء شركة الاتصالات الفلسطينية الخلوية (جوال)، والكثف عن الفروق بين استجابات أفراد العينة المبحوثة، تم توزيع استبانة للحصول على البيانات، أثنارت نتائج تحليل البيانات إلى وجود اثر ذو دلالة إحصائية بين أبعاد التسويق الفيروسي وتحسين الصورة الذهنية للشركة موضع الدراسة، وكذلك وجود فروق ذات دلالة إحصائية في منوسطات إجابات المبحوثين تعزى للمتغير ات الثخصية. كما خرجت الدر اسة بعدد من التوصيات.

دراسة ( النوافلة، 2020م، ي):- سعت الدراسة إلى التعرف على مدى فاعلية دور العلاقات العامة في تشكيل الصورة الذهنية للشركات لدى الجمهور الخارجي ( الصيادلة)، نوصلت نتائج الدراسة إلى أنَّ فاعلية الأساليب المستخدمة في بناء الصورة الذهنية للشركة قد حصلت على درجة منوسطة من إجابات المبحوثين، وكذلك العوامل المؤثرة في تحسين الصورة الذهنية. كما أظهرت النتائج أنَّ عملية التواصل بين الثركة وجمهور ها تعاني من بعض المعيقات في مقدمتها ضعف القدرة الاتصالية لممثلي الثركة مما ينعكس سلباً على الصورة الذهنية للشركة.

در اسة (زين العابدين،2019م،270-271):-هدفت هذه الدراسة إلى التعرُّف على الدور الاتصالي لأنشطة العلاقات العامة في قياس اتجاهات الجمهور نحو الجامعة ( قياس الصورة الذهنية)، أستخدم المنهج الوصفي التحليلي عن طريق المسح الثامل لعدد 104 مبحوث من ممارسي العلاقات العامة في خمس جامعات حكومية رئيسة في بغداد، وتم جمع البيان بواسطة الاستبيان، وتوصلت نتائج الدراسة إلى وجود علاقة ارتباط ذات دلالة معنوية بين النشاط الاتصالي للمؤسسة الجامعية ومتطلبات ممارسي العلاقات العامة في الجامعة، وكذلك وجود علاقة ارتباط ذات دلالة معنوية بين النشاط الاتصالي للجامعة و العلاقات العامة الإلكترونية. كما خرجت الدر اسة بعدد من التوصيات.

دراسة (عبد الخير وبدوي و عبد الله،2017):- هدفت هذه الدراسة إلى معرفة والتحقق من أثر الثقافة التنظيمية على إدارة الصورة الذهنية بوزارة التخطيط والمرافق العامة في ولاية القضارف بالسودان، اتبعت الدراسة المنهج الوصفي التحليلي، وقد وزع استبيان على عينة عثوائية من الموظفين البالغ عددهم 96. وباستخدام التحليل الإحصائي أظهرت النتائج وجود علاقة قوية موجبة وذات دلالة إحصائية معنوية بين الثقافة التنظيمية إدارة الصورة الذهنية، وأنَّهَ يوجد نأثثير معنوي للتقافة التنظيمية على إدارة الصورة الذهنية يرجع لثناثة متغيرات هي العدالة، فرق العمل، والصفوة، كما خرجت بعدد من 
در اسة ( محي الدين ومحمود، 2017م، 311):-هدفت الدراسة إلى التعرُّف على دور أخلاقيات العمل في تحسين الصورة الذهنية للمنظمات، وهي دراسة اسنطلاعية، نمّ فيها استقصاء آراء عينة من العاملين في بعض المنظمات الخدمية الربحية العاملة في إقليم كوردستان العراق و البالغ عددهم 117 مبحوث، وذلك باستخدام الاستبيان لجمع البيانات التي تم تحليلها عن طريق برنامج SPSS باستخدام معامل الارتباط وتحليل الانحدار البسيط والمتعدد، توصلت نتائج التحليل إلى وجود علاقة

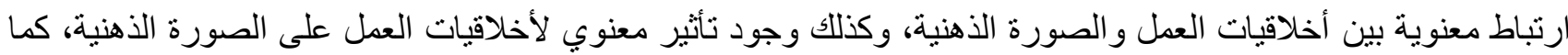
خرجت الدر اسة بعدد من التوصيات.

در اسة (القبلان،2016م،1):- هدفت الدر اسة إلى الكثف عن الصورة الذهنية لمهنة المكتبات و المعلومات من خلال دراسة علمية بإتباع المنهج الوصفي التحليلي، وذلك كمحاولة لمعرف كيف يرى المجتمع هذه المهنة، وكان مجتمع الدراسة يثمل كافة أطياف المجتمع في السعودية، وباستخدام الاستبيان الذي وزع إلكترونياً على وسائل التو اصل الاجتماعي، جاء حجم العينة بعدد 234 ممثلاً فيه السعوديين و غير هم من الجنسيات ومن كل الأعمار و المستويات التعليمية. وكانت النتائج تشير إلى تنوش وعدم

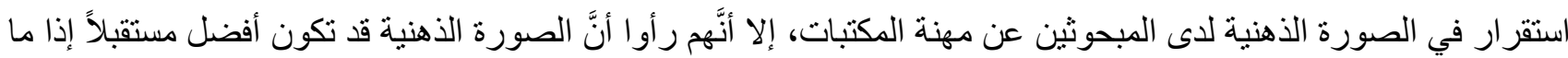
تُمَّ القيام بعدد من الإجر اءات لتعزيز ها بالاستفادة من التقنية الحديثة من خلال شبكات التو اصل الاجتماعي. وبناءاً على نتائج التحليل نمَّ اقتر اح عدد من التوصيات لتعزيز الفهم الحقيقي لمهنة المكتبات و المعلومات، وذللك من أجل رفع الانطباعات الذاتية للأفر اد بما يتو افق مع الطموح المستقبلي لهذه المهنة. تعقيب على الاراسات السابقة ومقارنتها بالدراسة الحالية:-

اتفقت الدر اسة الحالية مع بعض الدر اسات السابقة في استخدام العينة والاستبيان كأداة لجمع البيانات، أما أوجه الفرق فقد ظهرت فيما يتعلق بمتغيري الدراسة، بالنسبة للمتغير المستقل سلوك المواطنة التنظيمية لاحظت الباحثة أنَّ معظم الدراسات التي نمَّ سردها كدر اسات سابقة قد جعلته متغيراً تابعاً مثل در اسة (عطية والمقدم، 2018م)، ودراسة ( سعيد، 2017م)، ودر اسة (المصري، 201 5)، ودر اسة (Acaray\& Akturan,2015)، إلا أنَّ هناك دراسة واحدة قد جعلته متغيراً مستقلاً وهي دراسة( سعدون؛ وغيات؛ وبزايد،2017م)، بينما هناك دراسة قريبة الثبه من هذه الدراسة وهي دراسة (رسول، 2016م) التي حاولت التعرف على واقع سلوك المواطنة التنظيمية لدى المبحوثين إلا أنها لم تربطه بأي متغير آخر، وكذلك در اسة ( شهري ،2019م) فقد كانت اكثر تشابهاً مع هذه الدر اسة حيث ركزت على معرفة مدى ممارسة أعضاء هيئة التدريس بـاء لسلوك المواطنة التنظيمية لكنها لم تربطه بمتغير الصورة الذهنية، مما جعل الدراستين مختلفين عن الدراسة الحالية. أما المتغير التابع وهو الصورة الذهنية فقد جعلته معظم الدراسات السابقة المذكورة متغير تابع أيضاً ـ مما يجعلها مشابهة لهذه الدر اسة ـ مثل دراسة ( عبد الخير وبدوي و عبد اله، 2017م)، ودر اسة ( محي الدين؛ ومحمود، 2016م)، وحاولت دراسة ( القبلان، 2016م) الكثف عن الصورة الذهنية دون ربطها بأي متغير فكانت مختلفة. وبالتالي يمكن القول بأنَّ الدراسة الحالية مختلفة عن الدر اسات المذكورة من حيث متغير اتها، وكذلك من حيث البيئة المكانية. 
المبحث الثاني: الإطار التطبيقي للار استة

ينم في هذا الجزء مـن الدر اسـة تسليط الضـوء على الجانب التطبيقي للار اسـة، وذلك مـن خـلال إجراءات الدراسـة الميدانية في جامعـة أم درمـان الإسـامية (مجمع الطالبات)، وباستعمال أداة الدراسـة المتمثلة في الاستبيان، حيث يتم عرض

وتحليل النتائج وكذللك اختبار الفرضيات.



منهج الاراسة: إنَّ المنهج المناسب من أجل وصف وتحليل الدراسة بأكملها هو المنهج الوصفي التحليلي، لوصف سلوك المو اطنة التنظيمية و علاقته بالصورة الذهنية، كما نمَّ استخدام المنهج التحليلي لتحليل معطيات الجانب الميداني. مجتمع الدراسة: انطلافاً من المجال الموضوعي للار اسة، ونساؤ لاتها، وطبيعة البيانات المطلوبة، والأهداف التي تسعى باته الدر اسة لتحقيقها، حددت الباحثة مجتمع الدر اسة من عضوات هيئة التدريس والموظفات بمجمع الطالبات بجامعة أم درمان

الإسلامية والبالغ عددهم (1116)، حيث تمثل عضوات هيئة التدريس (571)، و الموظفات (545) (حامد:2019م). عينة الارراسة: نمّّ اختيار عينة الدراسة بطريقة العينة العشوائية الطبقية من المجتمع المدروس مكونة من نسبة (10\%) لكل طبقة منهما، حيث بلغ عدد عضوات هيئة التدريس (57,1) أب (57) عضوة، بينما عدد الموظفات كان (54,5) أي (55) موظفة، أي ما مجمو عه (112) مفردة، و نم توزيع عدد (112) استبانة على عينة الدراسة ونم استرجاعها كلها،

منها (105) استبانة سليمة، نم استخدامها في التحليل بنسبة استرجاع بلغت (93,75\%)، بياناتها موضحة في جدول (1) جدول (1): الاستبيانات الموزعة والمعادة

\begin{tabular}{|c|c|c|}
\hline النسبة\%\% & العدد & 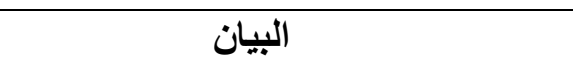 \\
\hline$\% 93,75$ & 105 & الاستبيانات المعادة و الصالحة للتحليل \\
\hline$\% 6,25$ & 7 & الاستبيانات المعادة و الغير صالحة للتحليل \\
\hline$\% 0,0$ & 0 & الاستبيانات التي لم يتم إرجاعها \\
\hline$\% 100$ & 112 & مجموع الاستبيانات الموزعة \\
\hline
\end{tabular}

المصدر: إعداد الباحثة، من بيانات الاراسة الميدانية، 2020م

2- أداة الدراسة: بالاعتماد على ماورد في الإطـار النظري و الدراسـات السـابقة، تم بنـاء استبيان خصيصـاً لقياس اتجاهـات مفردات العينة، وفقا للأبعاد الرئيسة للدر اسة، وقد قسم هذا الاستبيان إلى جز أين:

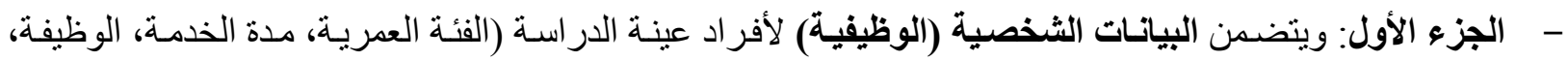
و المؤهل العلمي).

- - الجزء الثاني: البيانـات الأساسية (الموضوعية): ويشتمل على أبعاد الدراسـة والتي من خلالها يتم التعرف على متغير ات الدر اسة، ويشتمل هذا القسم على ستة أبعاد و عدد (35) عبارة تمثل متغير ات الدر اسة وفقاً لما يلي:البُعد الأول: يقيس (الإيثار) ويشتمل على عدد (5) عبار ات. البُعد الثاني: يقيس (الكياسة) ويشتمل على عدد (5) عبار اتلات. البُعد الثالث: يقيس (الروح الرياضية) ويشتمل على عدد (5) عبار ات. 
المجلة الدولية لنشر البحوث والدراسات

International Journal of Research and Studies Publishing
المجلد الثالث - الإصدار الثامن والعشرون تأريخ الإصدار: 20 فبراير 2022 م

البُعد الرابع: يقيس (السلوك الحضاري) ويشتمل على عدد (5) عبار ات.

البُعد الخامس: يقيس (وعي الضمير) ويشتمل على عدد (5) عبار ات.

البُعد السادس: يقيس (الصورة الذهنية) ويشتمل على عدد (10) عبار اتئي

كما تم قياس درجة الاستجابات حسب مقياس ليكرت الخماسى (Likart Scale)، و الذي يتر اوح من

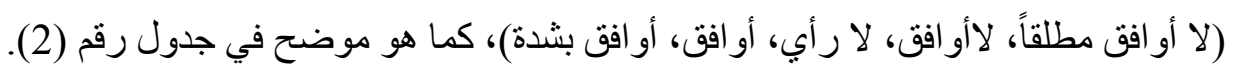

جدول (2): الميزان التقديري لمقياس ليكرت الخماسي

\begin{tabular}{|c|c|c|c|c|}
\hline المستوى & الاتجاه & الوسط المرجح & الوزن النسبي & درجة الموافقة \\
\hline \multirow{2}{*}{ منخفض } & عدم المو افقة مطلقاً & $1,79-1$ & 1 & لا أو افق مطلقاً \\
\hline & عدم المو افقة & $2,59-1,80$ & 2 & لا أو افق \\
\hline متوسط & الحياد & $3,39-2,60$ & 3 & لا رأي \\
\hline \multirow{2}{*}{ مرتفع } & المو افقة & $4,19-3,40$ & 4 & أو افق \\
\hline & المو افقة بشدة & $5-4,20$ & 5 & أو افق بشدة \\
\hline
\end{tabular}

المصدر: إعداد الباحثة، من التحليل الإحصائي SPSS، 2020م

صدق وثبات أداة الدراسة: سيتم التركيز هنا على أداة الدراسة المتمثلة في الاستبيان من حيث صدقها، وكذلك من خـلال حساب معامل ألفا كرونباخ الذي يقيس مدى ثبات هذه الأداة وصلاحيتها للنطبيق الميداني. أـ صدق أداة الدراسة: للنأكد من صدق أداة الدر اسة قامت الباحثة بإجر اء نوعين من الاختبار ات هما:•الصدق الظاهري (صدق المحكمين): تطلب التحقق من الصدق الظاهري لأداة الدراسة الاستعانة بمجمو عة من المحكمين المتخصصين في إدارة الأعمال بقصد الاستفادة من خبرتهم في اختصاصاتهم لمعرفة مدى مناسبة العبار ات الواردة في الاستبيان لموضوع الدراسة وهدفها. وبناءاً على ملاحظات الأساتذة تم تعديل الاستبيان وتصميمه في صورته النهائية، مما جعل المقياس أكثر دقة وموضو عية في القياس. •الصدق البنائي:Structure Validity: يعتبر الصدق البنائي أحد مقاييس صدق الأداة الذي يقيس مدى تحقيق الأهداف التي تريد الأداة الوصول إليها، ويبين مدى ارتباط كل بُعد من أبعاد الدراسة مع الدرجة الكلية لفقرات الاستبيان، وقد

قامت الباحثة باستخدام معامل ارتباط بيرسون للتحقق من ذللك كما في جدول (3). جدول (3): معامل الارتباط بين درجة كل بُعد من الاستبيان والدرجة الكلية للاستبيان

\begin{tabular}{|c|c|c|}
\hline مستوى الدلالة & معامل ارتباط بيرسون & الأبعاد \\
\hline 0,000 & 0,616 & الإيثار \\
\hline 0,000 & 0,590 & الكياسة \\
\hline 0,000 & 0,684 & الروح الرياضية \\
\hline
\end{tabular}


ISSN: 2709-7064

\begin{tabular}{|c|c|c|}
\hline 0,000 & 0,686 & والسلوك الحضاري \\
\hline 0,000 & 0,661 & وعي الضمير (الالتزام العام) \\
\hline 0,000 & 0,796 & الصورة الذهنية \\
\hline
\end{tabular}

* معامل الارتباط دال إحصائياً عند مستوى دلالة معنوية أقل من (0,05)

\section{المصدر: إعداد الباحثة، من نتائج التحليل الإحصائي SPSS، 2020م}

يتضح من جدول (3) أنَّ جميع معاملات الارتباط في جميع أبعاد الاستبيان دالة إحصائية عند مستوى دلالة أقل من

(0,05)، كما تراوحت قيمة معامل الارتباط ما بين (0,590) كحد أدني و(0,796) كحد أعلى، وتعنى هذه القيم تو افر درجة

عالية من الصدق البنائي لأبعاد الدراسة ومن ثم يمكن القول بأنَّ المقاييس التي اعتمدت عليها الباحثة في قياس أبعاد الدراسة تتمتع بالصدق البنائي، مما يمكن من الاعتماد على هذه الإجابات في تحقيق أهداف الدراسة وتحليل نتائجها، وبذلك تعتبر جميع أبعاد الاستبيان صادقة لماوضعت لقياسه.

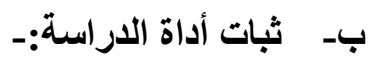

من أجل التأكد من ثبات أداة الدراسة، والذي يعني أنَّ النتائج ستكون نفسها تقريباً إذا ما تكرر تطبيقها على أفراد العينة أنفسهم، وقد تمَّ اختبار ها عن طريق معامل ألفا كرونباخ (Cronbach's Alpha)، وتكون القيمة مقبولة إحصائياً لهذا المقياس عندما تعادل (60\%) فأكثر ، وقد جاءت النتائج كما في جدول (4). جدول (4): الصدق الذاتي لأبعاد الاراسة باستخذام معامل (ألفا كرونباخ)

\begin{tabular}{|c|c|c|c|c|}
\hline الصدق & كرونباخ ألفا & عدد & 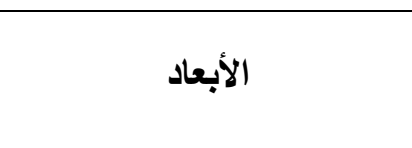 & b \\
\hline 0,809 & 0,655 & 5 & الإيثار & 1 \\
\hline 0,817 & 0,668 & 5 & الكياسة & 2 \\
\hline 0,852 & 0,726 & 5 & الروح الرياضية & 3 \\
\hline 0,838 & 0,702 & 5 & السلوك الحضاري & 4 \\
\hline 0,827 & 0,684 & 5 & وعي الضمير (الالتزام العام) & 5 \\
\hline 0,946 & 0,894 & 10 & الصورة الأهنية & 6 \\
\hline 0,947 & 0,897 & 35 & جميع العبارات & \\
\hline
\end{tabular}

* الصدق الأتي: هو عبارة عن الجذر التربيعي لمعامل الثبات

المصدر: إعداد الباحثة، من نتائج التحليل الإحصائي SPSS، 2020م

بظهر من جدول رقم (4) أنَّ قيم معامل ألفا كرونباخ كلها مرتفعة، حيث بلغت قيمة معامل ألفا كرونباخ الخاصة بالأبعاد (0,655) في أدني قيمة له و (0,894) في أقصى قيمة له، 
كما بلغت قيمة معامل ألفا كرونباخ الخاصة بالاستبيان ككل (0,897)، وكذلك كانت قيمة الصدق الذاتي مرتفعة لكل بُعد من أبعاد الاستبيان وكانت قيمة الصدق الذاتي لجميع فقرات الاستبيان (0,947)، وهذا يعني أنَّ معامل الصدق الذاتي مرتفع، وبشكل عام ما دامت كل القيم أكبر من (60\%) فهذا يعني أنَّ الاستبيان يتمنع بدرجة ثبات مرتفعة تجعل منه أداة مقبولة جداً وصالحة للار اسة.

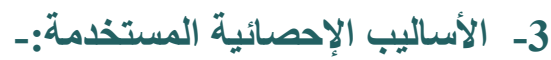

قامت الباحثة بتحليل البيانـات التي تم جمعها مـن خـلال الاستبيان باستخدام الحزمـة الإحصـائية للعلوم الاجتماعيـة (SPSS) وقد تم الاعتمـاد على عدد معين من الأسـاليب الإحصـائية في تحليل البيانات التي احتو اهـا الاستبيان وتمثلت هذه الأساليب فيما يلي:1- التكرار والنسب المئوية: لوصف خصائص عينة الدر اسة وتحديد استجابات أفر ادها تجاه عبار ات الاستبيان. 2- الوسط الحسابي (Mean): لقياس مدى تحقق كل عبارة من عبار ات أداة الدر اسـة، و الوسط الحسـابي الإجمـالي (العام) لكل بُعد من أبعاد الاستبيان، وذلك من أجل ترتيب العبار ات حسب الأهمية لنتائج الدراسة. 3- الانحراف المعياري (Standard Deviation): للتعرف على مدى انحر اف (تشتت) استجابات أفر اد الدر اسـة لكل عبارة من عبار ات متغير ات الدراسة، ولكل بُعد من الأبعاد الرئيسية عن وسطها الحسابي. 4- معامل ألفا كرونباخ (Cronbach's Alpha):- للتحقق من ثبات عبار ات الاستبيان. 5- معامـل ارتبـاط بيرسون (Pearson Correlation):- لمعرفة العلاقة بين المتغير ات المستقلة و التابعة و التحقق من الصدق البنائي لعبار ات الاستبيان. 6- استخدام تحليل التباين الأحسادي (ONE WAY ANOVA): للتعرف على مـا إذا كانت هنالك فروق ذات دلالـة إحصائية في اتجاهات أفر اد مجتمع الدراسة حول أبعاد الدر اسة باختلاف متغير اتهم الثخصية و الوظيفية التي تنقسم إلى أكثر من فئتين. ثُانياً: عرض وتحيل النتائج واختبار فرضيات الار اسة:ة. 4- مناقشة تحليل البيانات الشخصية: يتضمن هذا العنصر تحليلاً مفصلاً للخصائص الثخصية التي نمَّ جمعها من عينة الدر اسة في جامعة أم درمان الإسلامية (مجمع الطالبات)، وجدول (5) يوضح ذللك. جدول (5): توزيع أفراد العينة حسب الخصائص الثخصية

\begin{tabular}{|c|c|c|c|}
\hline النسبة المئوية \% & التكرار & البيانات الشخصية & المتغيرات \\
\hline $8,6 \%$ & 9 & 20 و أقل من 30 سنة & \multirow{5}{*}{ الفئة العمرية } \\
\hline $29,5 \%$ & 31 & 30 و أقل من 40 سنة & \\
\hline $38,1 \%$ & 40 & 40 و أقل من 50 سنة & \\
\hline $23,8 \%$ & 25 & 50 سنة فأكثر & \\
\hline$\% 100$ & 105 & المجموع & \\
\hline$\% 10,5$ & 11 & أقل من 5 سنة & مدة الخدمة \\
\hline
\end{tabular}


المجلة الدولية لنشر البحوث والدراسات

International Journal of Research and Studies Publishing
المجلد الثالث - الإصدار الثامن والعشرون تأريخ الإصدار: 20 فبراير 2022 م

ISSN: 2709-7064

\begin{tabular}{|c|c|c|c|}
\hline$\% 31,4$ & 33 & 5 و أقل من 15 سنة & \\
\hline$\% 38,1$ & 40 & 15 و أقل من 25 سنة & \\
\hline$\% 20,0$ & 21 & 25 سنة فأكثر & \\
\hline$\% 100$ & 105 & المجموع & \\
\hline$\% 40,0$ & 42 & موظف & \multirow{5}{*}{ الوظيفة } \\
\hline$\% 3,8$ & 4 & رئيس قسم & \\
\hline$\% 5,7$ & 6 & مدير إدارة & \\
\hline$\% 50,5$ & 53 & عضو هيئة تدريس & \\
\hline$\% 100$ & 105 & المجموع & \\
\hline$\% 8,6$ & 9 & شُهادة ثانوية & \multirow{4}{*}{ المؤهل العلمي } \\
\hline$\% 22,8$ & 24 & جامعي & \\
\hline$\% 68,6$ & 72 & فوق الجامعي & \\
\hline$\% 100$ & 105 & المجموع & \\
\hline
\end{tabular}

المصدر: إعداد الباحثةة، من نتائج التحليل الإحصائي SPSS، 2020م

يتبين من نتائج جدول (5) ما يلي:-

توزيع أفراد العينة حسب متغير الفئة العمرية: يُلاحظ من الجدول السابق أنَّ المبحوثات اللاتي تتر اوح أعمار هن من (40 و أقل من 50 سنة) سجلن أعلى نسبة بو اقع (38,1\%)، تليهم فئة اللاتي تتر اوح أعمار هن مـا بين (30 و أقل من 40 سنة) بنسبة (29,5\%)، تلتها فئة اللاتي تتر اوح أعمار هن ما بين (50 سنة فأكثر) بنسبة (23,8\%)، و أخير أ سجلت فئة اللاتي تتر اوح أعمار هن (20 و أقل من 30 سنة) أقل نسبة (8,6\%). و عليه يُلاحظ أنَّ أكثر من (76,2\%) أب أكثر من نصف

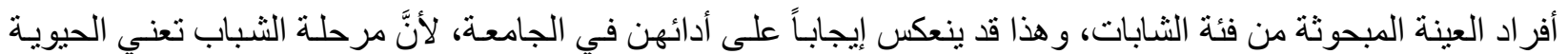
و النشاط وبالتالي العطاء الثَّري. توزيع أفراد العينة حسب متفير مدة الخدمة: يبين الجدول السابق أنَّ فئة اللاتي تتراوح مدة خدمتهن ما بين (15 وأقل من 25 سنة) جاءت في المرتبة الأولى بنسبة (38,1\%)، تليها فئة اللاتي تر اوحت مدة خدمتهن (5 و أقل من 15 سنة) بنسبة (31,4\%)، ثم تلتها فئة اللاتي تراوحت مدة خدمتهن (25 سنة فأكثر) بنسبة بلغت (20\%)، وجـاءت في المرتبـة الأخيرة فئسة اللاتـي تراوحت مدة خدمنهن (أقل مـن 5 سـنة) وذلك بنسبة بلغت (10,5\%). عليه

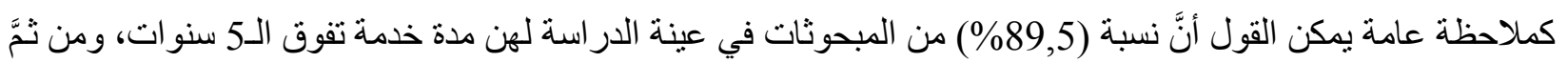
فهنَّ مؤ هلات للعطاء أكثر إذا توفرت الظروف البيئية الملائمة. توزيع أفراد العينة حسب متغير الوظيفة: تبين نتائج الجدول أنَّ عضوات هيئة التدريس كانت نسبتهن أعلى حيث بلغت (50,3\%)، ثم تلتها نسبة الموظفات بمقدار (40\%)، بينما بلغت نسبة مدير ات الإدار (5,7\%)، وجاءت نسبة رئيسات

$$
\text { الأقسام أخيراً حيث بلغت (\%) (\%). }
$$


توزيـع أفراد العيـة حسب متغير المؤهل العلمي: يظهر مـن الجدول السـابق أنَّنسبة الحاصـلات على الثـهادات فوق الجامعية سيطرت على التوزيع إذ بلغت نسبتهن (68,6\%)، ثم تلتها فئسة الحاصلات على الثهادات الجامعية حيث بلغت نسبتهن (22,8\%)، و أخيراً جاءت فئة الموظفات الحاصـلات على شـهادة ثانويـة إذ بلغت نسبتهن (8,6\%). من خلال مـا سبق يلاحظ أن نسبة (01,4\%) من المبحوثات حاصـلات على شـهادات جامعية وفوق الجامعيـة، وهذا مؤشر جيد يمثل المستوى المعرفي العالي للعاملات بالجامعة سو اء من عضوات هيئة التدريس أو الموظفات. 5- التوزيع التكراري والإحصاء الوصفي لأبعاد الدراسة:-


المعياري، وذلك للتعرف على درجة المو افقة بين أفر اد عينة الدراسة تجاه عبار ات أبعاد الدراسة، وفيما يلي التوزيع التكراري و الإحصاء الوصفي لكل بُعد على حده 1- تحليل ومناقشة عبار وات بُعد الإيثار:تهدف الباحثة من خلال تحليل ومناقتشة عبار ات هذا البُعد معرفة آر اء عينة الدر اسـة حول مدى توفر بُعد الإيثار للى المبحوثات، حيث جاءت النتائج موضحة كما في جدول (6). جدول (6): التوزيع التكراري والإحصاء الوصفي لإجابات عينة الدراسة حول بُعد الإيثار

\begin{tabular}{|c|c|c|c|c|c|c|c|c|c|}
\hline \multirow{2}{*}{ الاتجاه } & \multirow{2}{*}{ الالمعياري } & \multirow{2}{*}{ الحسابي } & \multicolumn{5}{|c|}{ درجة الموافقة لبُعد الإيثار } & \multirow{2}{*}{ والتكرار } & \multirow[b]{2}{*}{ 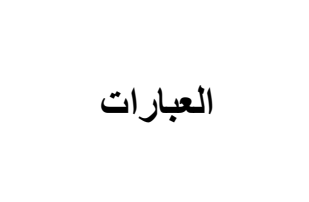 } \\
\hline & & & لا أوافق & $\begin{array}{c}\text { أوافق } \\
\text { أو }\end{array}$ & لأي & أوافق & أوافق & & \\
\hline \multirow[b]{2}{*}{ أو افق بشدة } & \multirow[b]{2}{*}{0,637} & \multirow[b]{2}{*}{4,70} & 0 & 3 & 1 & 21 & 80 & عدد & \multirow{2}{*}{ أسـاعد زملائي على القيام بالمهام الموكلة } \\
\hline & & & $\% 0,0$ & $\% 2,9$ & $\% 1,0$ & $\% 20,0$ & $\% 76,2$ & $\%$ & \\
\hline \multirow[b]{2}{*}{ أو افق بشدة } & \multirow[b]{2}{*}{0,474} & \multirow[b]{2}{*}{4,67} & 0 & 0 & 0 & 35 & 70 & عدد & \multirow{2}{*}{ لزأقدم المساعدة لأئي عندما يكون } \\
\hline & & & $\% 0,0$ & $\% 0,0$ & $\% 0,0$ & $\% 33,3$ & $\% 66,7$ & $\%$ & \\
\hline \multirow[b]{2}{*}{ أو افق بشدة } & \multirow[b]{2}{*}{0,449} & \multirow[b]{2}{*}{4,72} & 0 & 0 & 0 & 29 & 76 & عدد & \multirow{2}{*}{$\begin{array}{r}\text { أتعاون مع رؤسائي } \\
\text { أحساء الأعمال على وجه }\end{array}$} \\
\hline & & & $\% 0,0$ & $\% 0,0$ & $\% 0,0$ & $\% 27,6$ & $\% 72,4$ & $\%$ & \\
\hline \multirow[b]{2}{*}{ أو افق بشدة } & \multirow[b]{2}{*}{0,432} & \multirow[b]{2}{*}{4,79} & 0 & 0 & 1 & 20 & 84 & عدد & \multirow{2}{*}{ أقُوم بمساعدة الزملاء } \\
\hline & & & $\% 0,0$ & $\% 0,0$ & $\% 1,0$ & $\% 19,0$ & $\% 80,0$ & $\%$ & \\
\hline أو افق بشدة & 0,565 & 4,60 & 0 & 0 & 4 & 34 & 67 & عدد ع اد & أقدم مصلحة العمل \\
\hline
\end{tabular}


المجلة الدولية لنشر البحوث والدراسات

International Journal of Research and Studies Publishing
المجلد الثالث - الإصدار الثامن والعشرون تأريخ الإصدار: 20 فبراير 2022 م

ISSN: 2709-7064

\begin{tabular}{|c|c|c|c|c|c|c|c|c|c|}
\hline & & & $\% 0,0$ & $\% 0,0$ & $\% 3,8$ & $\% 32,4$ & $\% 63,8$ & $\%$ & على المصلحة \\
\hline أوافق & 0,335 & 4,70 & & & & لإيثار & جمالي بُعد & & \\
\hline
\end{tabular}

المصدر: إعداد الباحثة، من نتائج التحليل الإحصائي SPSS، 2020م

يتضح من جدول (6) أنَّ نوفر بُعد الإيثار في جامعة أم درمان الإسلامية من وجهة نظر عينة الدراسة كان نتائجه مرتفعة، حيث بلغ الوسط الحسابي لبُعد الإيثار (4,70) وبانحر اف معياري (0,335)، وهذا يدل على أنَّ أفراد عينة الدراسة يوافقون بشدة على توفر بُعد الإيثار.

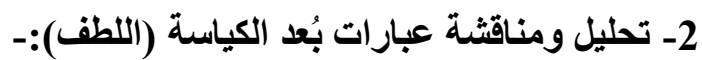
تهدف الباحثنة من خـلال تحليل ومناقتــة عبـار ات هذا البُعد معرفـة آر اء عينـة الدر اسـة حول مدى توفر بُعد الكياسـة (اللطف) في المبحوثات، حيث كانت النتائج موضحة كما في جدول (7). جدول (7): التوزيع التكراري والإحصاء الوصفي لإجابات عينة الدراسة حول بُعد الكياسة (اللطف)

\begin{tabular}{|c|c|c|c|c|c|c|c|c|c|}
\hline \multirow{2}{*}{ الاتجاه } & \multirow{2}{*}{ الالمعراف } & \multirow{2}{*}{ الحسابي } & \multicolumn{5}{|c|}{ درجة الموافقة لبُعد الكياسة (اللطف) } & \multirow{2}{*}{ والنسبة } & \multirow[b]{2}{*}{ 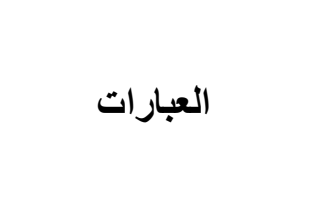 } \\
\hline & & & لا أوافق & $\begin{array}{c}\text { أوافق } \\
\text { أو }\end{array}$ & لا لأي & أوافق & بشدة أوافق & & \\
\hline \multirow{2}{*}{ أو افق بشدة } & \multirow{2}{*}{0,387} & \multirow{2}{*}{4,85} & 0 & 0 & 1 & 14 & 90 & عدد & \multirow{2}{*}{ أتجنب افتعال المشـاكل } \\
\hline & & & $\% 0,0$ & $\% 0,0$ & $\% 1,0$ & $\% 13,3$ & $\% 85,7$ & $\%$ & \\
\hline \multirow[b]{2}{*}{ أو افق بشدة } & \multirow[b]{2}{*}{0,649} & \multirow[b]{2}{*}{4,44} & 0 & 1 & 6 & 44 & 54 & عدد & \multirow{2}{*}{ فر أقـوم بمشـورة زملائي } \\
\hline & & & $\% 0,0$ & $\% 1,0$ & $\% 5,7$ & $\% 41,9$ & $\% 51,4$ & $\%$ & \\
\hline \multirow{2}{*}{ أو افق بشدة } & \multirow[b]{2}{*}{0,615} & \multirow[b]{2}{*}{4,67} & 0 & 2 & 2 & 25 & 76 & عدد & \multirow{2}{*}{ في أبتعد عن التـدخل في } \\
\hline & & & $\% 0,0$ & $\% 1,9$ & $\% 1,9$ & $\% 23,8$ & $\% 72,4$ & $\%$ & \\
\hline \multirow{2}{*}{ أو افق بشدة } & \multirow{2}{*}{0,563} & \multirow{2}{*}{4,61} & 0 & 0 & 4 & 33 & 68 & عدد & \multirow{2}{*}{ في الدعـم الـزملاء معنويـاً } \\
\hline & & & $\% 0,0$ & $\% 0,0$ & $\% 3,8$ & $\% 31,4$ & $\% 64,8$ & $\%$ & \\
\hline \multirow{2}{*}{ أو افق بشدة } & \multirow{2}{*}{0,434} & \multirow{2}{*}{4,82} & 0 & 0 & 2 & 15 & 88 & عدد & \multirow{2}{*}{ أحترم حقوق الآخرين } \\
\hline & & & $\% 0,0$ & $\% 0,0$ & $\% 1,9$ & $\% 14,3$ & $\% 83,8$ & $\%$ & \\
\hline أوافق & $\mathbf{0 , 3 5 3}$ & 4,68 & \multicolumn{7}{|c|}{ إجمالي بُعد الكياسة(اللطف) } \\
\hline
\end{tabular}




\section{المصدر: إعداد الباحثة، من نتائج التحليل الإحصائي SPSS، 2020م}

يتضح من جدول (7) أنَّ نوفر بُعد الكياسة (اللطف) في جامعة أم درمان الإسلامية من وجهة نظر عينة الدراسة كانت نتائجه مرتفعة، حيث بلغ الوسط الحسابي لبُعد الكياسة (اللطف) (4,68) وبانحر اف معياري (0,353)، وهذا يدل على أنَّ أفراد عبنة الدر اسة يو افقون بشدة على توفر بُعد الكياسة (اللطف).

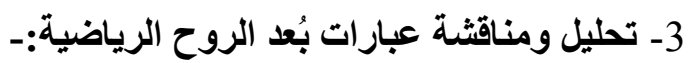
تهدف الباحثة من خلال تحليل ومناقثة عبار ات هذا البُعد معرفة آراء عينة الدر اسة حول مدى توفر بُعد الروح الرياضية

$$
\text { في المبحوثات، حيث كانت النتائج موضحة كما في جدول (8). }
$$

جدول (8): التوزيع التكراري والإحصاء الوصفي لإجابات عينة الاراسة حول بُعد الروح الرياضية

\begin{tabular}{|c|c|c|c|c|c|c|c|c|c|}
\hline \multirow{2}{*}{ الاتجاه } & \multirow{2}{*}{ الالمراف } & \multirow{2}{*}{ الحسابي } & \multicolumn{5}{|c|}{ درجة الموافقة لبُعد الروح الرياضية } & \multirow{2}{*}{ والتكرار } & \multirow[b]{2}{*}{ 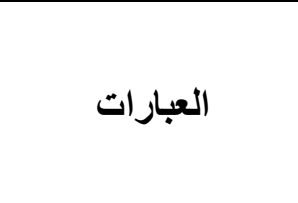 } \\
\hline & & & لا أوافق & لا لا أوافق & ل الا رأي & أوافق & أوافق & & \\
\hline \multirow{2}{*}{ أو افق } & \multirow{2}{*}{0,637} & \multirow{2}{*}{4,36} & 0 & 2 & 3 & 55 & 45 & 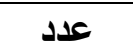 & \multirow{2}{*}{ 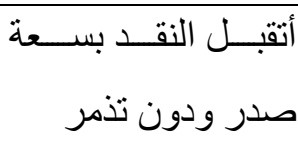 } \\
\hline & & & $\% 0,0$ & $\% 1,9$ & $\% 2,9$ & $\% 52,4$ & $\% 42,9$ & $\%$ & \\
\hline \multirow{2}{*}{ بشدة أو افق } & \multirow{2}{*}{0,617} & \multirow{2}{*}{4,42} & 0 & 2 & 1 & 53 & 49 & عدد ع اد & \multirow{2}{*}{  } \\
\hline & & & $\% 0,0$ & $\% 1,9$ & $\% 1,0$ & $\% 50,5$ & $\% 46,7$ & $\%$ & \\
\hline \multirow{2}{*}{ بثُوة أو افق } & \multirow{2}{*}{0,619} & \multirow{2}{*}{4,44} & 0 & 1 & 4 & 48 & 52 & عدد & \multirow{2}{*}{  } \\
\hline & & & $\% 0,0$ & $\% 1,0$ & $\% 3,8$ & $\% 45,7$ & $\% 49,5$ & $\%$ & \\
\hline \multirow{2}{*}{ بشدة } & \multirow{2}{*}{0,571} & \multirow{2}{*}{4,65} & 0 & 1 & 2 & 30 & 72 &  & \multirow{2}{*}{ التـزم بحـدودي تجــاه } \\
\hline & & & $\% 0,0$ & $\% 1,0$ & $\% 1,9$ & $\% 28,6$ & $\% 68,6$ & $\%$ & \\
\hline \multirow{2}{*}{ 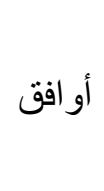 } & \multirow{2}{*}{0,997} & \multirow{2}{*}{3,88} & 4 & 5 & 20 & 47 & 29 & عدد & \multirow{2}{*}{ أنابع دائمـاً الإعلانــات } \\
\hline & & & $\% 3,8$ & $\% 4,8$ & $\% 19,0$ & $\% 44,8$ & $\% 27,6$ & $\%$ & \\
\hline أوافق & 0,488 & 4,35 & \multicolumn{7}{|c|}{ إجمالي بُعد الروح الرياضية } \\
\hline
\end{tabular}

المصدر: إعداد الباحثة، من نتائج التحليل الإحصائي SPSS، 2020م

يتضح من جدول (8) أنَّ درجة توفر بُعد الروح الرياضية في جامعة أم درمان الإسلامية من وجهة نظر عينة الدراسة نتائجه كانت مرتفعة، حيث بلغ الوسط الحسابي لبُعد الروح الرياضية (4,35) وبانحر اف معياري (0,488)، و هذا يدل على أنَّ أفر اد عينة الدر اسة يو افقون بثدة على توفر بُعد الروح الرياضية. 
4- تحليل ومناقشة عبارات بُعد السلوك الحضاري:-


الحضاري في المبحوثات، حيث كانت النتائج موضحة كما في جدول (9). جدول (9): التوزيع التكراري والإحصاء الوصفي لإجابات عينة الدراسة حول بُعد السلوك الحضاري

\begin{tabular}{|c|c|c|c|c|c|c|c|c|c|}
\hline \multirow{2}{*}{ الاتجاه } & \multirow{2}{*}{ الاتحراف } & \multirow{2}{*}{ الكسابي } & \multicolumn{5}{|c|}{ درجة الموافقة لبُعد السلوك الحضاري } & \multirow{2}{*}{ والنسبة } & \multirow[b]{2}{*}{ 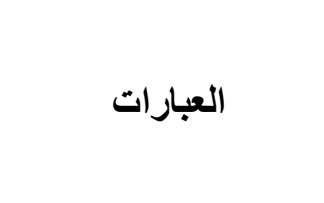 } \\
\hline & & & لا أوافق & لا لا أوافق & ل الأي & أوافق - & أوافث & & \\
\hline \multirow{2}{*}{ بثدة } & \multirow{2}{*}{0,458} & \multirow{2}{*}{4,70} & 0 & 0 & 0 & 31 & 74 & عدد & \multirow{2}{*}{ وأهتم بمستقبل المؤسســة } \\
\hline & & & $\% 0,0$ & $\% 0,0$ & $\% 0,0$ & $\% 29,5$ & $\% 70,5$ & $\%$ & \\
\hline \multirow{2}{*}{ أو افق } & \multirow{2}{*}{0,546} & \multirow{2}{*}{4,68} & 0 & 1 & 1 & 29 & 74 & عدد & \multirow{2}{*}{ 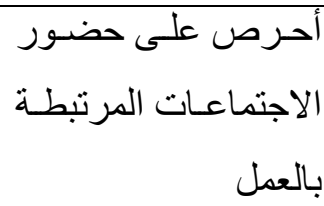 } \\
\hline & & & $\% 0,0$ & $\% 1,0$ & $\% 1,0$ & $\% 27,6$ & $\% 70,5$ & $\%$ & \\
\hline \multirow{2}{*}{ أو افث } & \multirow{2}{*}{0,832} & \multirow{2}{*}{4,22} & 0 & 4 & 15 & 40 & 46 & عدد & \multirow{2}{*}{ 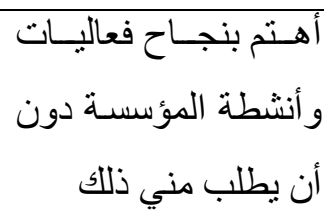 } \\
\hline & & & $\% 0,0$ & $\% 3,8$ & $\% 14,3$ & $\% 38,1$ & $\% 43,8$ & $\%$ & \\
\hline \multirow{2}{*}{ بثدة } & \multirow{2}{*}{0,428} & \multirow[b]{2}{*}{4,76} & 0 & 0 & 0 & 25 & 80 & عدد & \multirow{2}{*}{ أحسرص علـى تحسـين } \\
\hline & & & $\% 0,0$ & $\% 0,0$ & $\% 0,0$ & $\% 23,8$ & $\% 76,2$ & $\%$ & \\
\hline \multirow{2}{*}{ أو افق } & \multirow{2}{*}{0,667} & \multirow{2}{*}{4,49} & 0 & 2 & 4 & 40 & 59 & عدد & \multirow{2}{*}{ أتقــدم دائمـاً بمقترحسات } \\
\hline & & & $\% 0,0$ & $\% 1,9$ & $\% 3,8$ & $\% 38,1$ & $\% 56,2$ & $\%$ & \\
\hline أوافق & 0,408 & 4,57 & \multicolumn{7}{|c|}{ إجمالي بُعد السلوكَ الحضاري } \\
\hline
\end{tabular}

\section{المصدر: إعداد الباحثّة، من نتائج التحليل الإحصائي SPSS، 2020م}

يتضح من جدول (9) أنَّ درجة توفر بُعد السلوك الحضاري في جامعة أم درمان الإسلامية من وجهة نظر عينة الدراسة كانت نتائجه مرتفعة، حيث بلغ الوسط الحسابي لبُعد السلوك الحضاري (4,57) وبانحر اف معياري (0,408)، و هذا يدل على أن أفر اد عينة الدر اسة يو افقون بشدة على توفر بُعد السلوك الحضاري. 5- تحليل ومناقشة عبارات بُعد وعي الضمير (الالتزام العام):تهدف الباحثة من خلال تحليل ومناقتنة عبار ات هذا البُعد معرفة آراء عينة الدر اسة حول مدى توفر بُعد وعي الضمير (الالتز ام العام) في المبحوثات، حيث كانت النتائج موضحة كما في جدول (10). 
جدول (10): التوزيع التكراري والإحصاء الوصفي لإجابات عينة الدراسة حول بُعد وعي الضمير

\begin{tabular}{|c|c|c|c|c|c|c|c|c|c|}
\hline \multirow{2}{*}{ الاتجاه } & \multirow{2}{*}{ المعياري } & \multirow{2}{*}{ الوسابي } & \multicolumn{5}{|c|}{ درجة الموافقة لبُعد وعي الضمير (الالتزام العام) } & \multirow{2}{*}{ والنسبة } & \multirow[b]{2}{*}{ 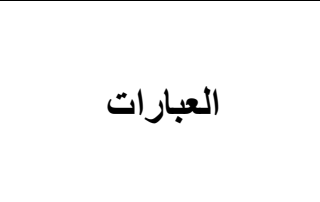 } \\
\hline & & & لا أوافق & لا أوافق & ل ل الا رأي & أوافق & بشدة أوافق & & \\
\hline \multirow{2}{*}{ بشدة أو افق } & \multirow{2}{*}{0,647} & \multirow{2}{*}{4,58} & 0 & 2 & 3 & 32 & 68 & عدد & \multirow{2}{*}{ 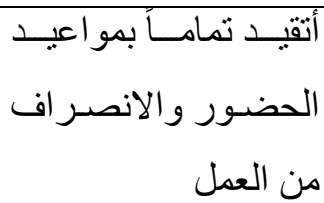 } \\
\hline & & & $\% 0,0$ & $\% 1,9$ & $\% 2,9$ & $\% 30,5$ & $\% 64,8$ & $\%$ & \\
\hline \multirow{2}{*}{ أو افقدة } & \multirow{2}{*}{0,543} & \multirow{2}{*}{4,69} & 0 & 1 & 1 & 28 & 75 & عدد & \multirow{2}{*}{ 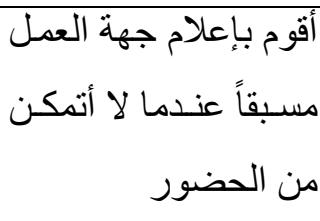 } \\
\hline & & & $\% 0,0$ & $\% 1,0$ & $\% 1,0$ & $\% 26,7$ & $\% 71,4$ & $\%$ & \\
\hline \multirow{2}{*}{ أو افقدة } & \multirow{2}{*}{0,76} & \multirow{2}{*}{4,47} & 1 & 1 & 8 & 33 & 62 & عدد & \multirow{2}{*}{ 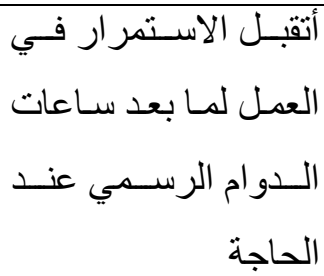 } \\
\hline & & & $\% 1,0$ & $\% 1,0$ & $\% 7,6$ & $\% 31,4$ & $\% 59,0$ & $\%$ & \\
\hline \multirow{2}{*}{ بشدة أو افق } & \multirow[b]{2}{*}{0,432} & \multirow[b]{2}{*}{4,79} & 0 & 0 & 1 & 20 & 84 & عدد & \multirow{2}{*}{  } \\
\hline & & & $\% 0,0$ & $\% 0,0$ & $\% 1,0$ & $\% 19,0$ & $\% 80,0$ & $\%$ & \\
\hline \multirow{2}{*}{ أو افق } & \multirow[b]{2}{*}{0,46} & \multirow[b]{2}{*}{4,78} & 0 & 0 & 2 & 19 & 84 & عدد & \multirow{2}{*}{ ألأجعامـــل بعنايــــة مــــع } \\
\hline & & & $\% 0,0$ & $\% 0,0$ & $\% 1,9$ & $\% 18,1$ & $\% 80,0$ & $\%$ & \\
\hline أوافق & 0,386 & 4,66 & \multicolumn{7}{|c|}{ إجمالي بُعد وعي الضمير (الالتزام العام) } \\
\hline
\end{tabular}

\section{المصدر: إعداد الباحثة، من نتائج التحليل الإحصائي SPSS، 2020م}

يتضح من جدول (10) أنَّ درجة توفر بُعد وعي الضمير (الالتز ام العام) في جامعة أم درمان الإسلامية من وجهة نظر عينة الدراسة كانت نتائجه مرتفعة، حيث بلغ الوسط الحسابي لبُعد وعي الضمير (الالنزام العام) (4,66) وبانحراف معياري (0,386)، و هذا يدل على أنَّ أفر اد عينة الدر اسة يو افقون بشدة على توفر بُعد وعي الضمير (الالتز ام العام). 6- تحليل ومناقثة عبار بات بُعد الصورة الذهنية:-

تهدف الباحثة من خلال تحليل ومناقثنة عبار ات هذا البُعد معرفـة آراء عينـة الدراسـة حول مدى بُعد الصورة الذهنيـة لدى المبحوثات، حيث كانت النتائج موضحة كما في جدول (11). 
جدول (11): التوزيع التكراري والإحصاء الوصفي لإجابات عينة الدراسة حول بُعد الصورة الذهنية






\begin{tabular}{|c|c|c|c|c|c|c|c|c|c|}
\hline \multirow[b]{2}{*}{ أو افق - } & \multirow[b]{2}{*}{1,087} & \multirow[b]{2}{*}{3,61} & 4 & 13 & 27 & 37 & 24 & 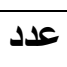 & \multirow{2}{*}{ 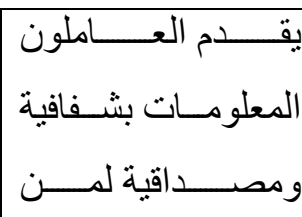 } \\
\hline & & & $\% 3,8$ & $\% 12,4$ & $\% 25,7$ & $\% 35,2$ & $\% 22,9$ & $\%$ & \\
\hline \multirow[b]{2}{*}{ أو افق - } & \multirow[b]{2}{*}{1,039} & \multirow[b]{2}{*}{3,84} & 5 & 7 & 15 & 51 & 27 & عدد & \multirow{2}{*}{ 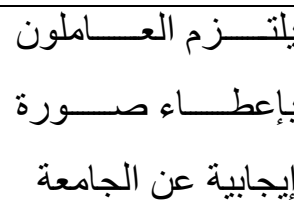 } \\
\hline & & & $\% 4,8$ & $\% 6,7$ & $\% 14,3$ & $\% 48,6$ & $\% 25,7$ & $\%$ & \\
\hline أوافق & 0,741 & 3,69 & \multicolumn{7}{|c|}{ إجمالي بُعد الصورة الذهنيً } \\
\hline
\end{tabular}

\section{المصدر: إعداد الباحثة، من نتائج التحليل الإحصائي SPSS،}

يتضح من جدول (11) أنَّ درجة توفر بُعد الصورة الذهنية عن جامعة أم درمان الإسلامية من وجهة نظر عينة الدراسة كانت فيها مرتفعة، حيث بلغ الوسط الحسابي لبُحد الصورة الذهنية (3,69) وبانحر اف معياري (0,741)، وهذا يدل على أن إن أفر اد عينة الدر اسة يو افقون على بُعد الصورة الذهنية.

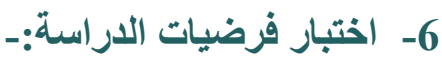

قامت الباحثة باستخدام معامل الارتباط بيرسون لمعرفة العلاقة بين المتغير المستقل (سلوك المواطنة التنظيمية) بأبعاده المختلفة و المتغير التابع (الصورة الذهنية). حيث يتم قبول الفرضية إذا كانت قيمة معامل الارتباط عند مستوى دلالـة معنويـة (0,05)، ويتم رفض الفرضية إذا كانت قيمـة معامـل الارتبـاط عند مسنتوى دلالـة معنويـة > (0,05)، وفيمـا يلي اختبـار كل فرضية على حده.

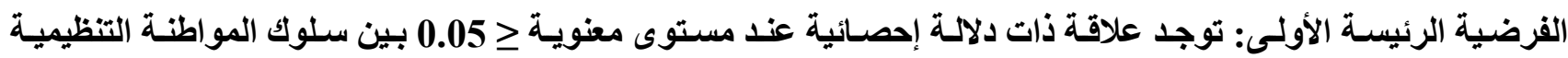
لعضوات هيئة التدريس والموظفات بجامعة أم درمان الإسلامية وتحسين الصورة الذهنية للجامعة. وتفر عت منها الفرضيات الفر عية التالية و التي يوضح اختبار ها فيما يلي:1/ توجد علاقة ذات دلالة إحصائية عند مستوى معنوية ج 0.05 بين الإيثار لاى عضوات هيئة التدريس و الموظفات بجامعة أم درمان الإسلامية وتحسين الصورة الذهنية للجامعة. قامت الباحثة باستخدام معامل الارتباط بيرسون لمعرفة العلاقة بين المتغير المستقل (الإيثار) و المتغير التابع (الصورة الذهنية) وجاءت قيم معامل الارتباط للفرضية الأولى كما في جدول (12). جدول (12): يوضح العلاقة بين (الإيثار) و(الصورة الذهنية)

\begin{tabular}{|c|c|}
\hline 0,220 & قيمة معامل الارتباط (r) \\
\hline 0,024 & مستوى الدلالة \\
\hline دال (توجد علاقة طردية ضعيفة) & القرار \\
\hline
\end{tabular}

* معامل الارتباط دال إحصائياً عند مستوى دلالة معنوية أقل من (0,05) المصدر: إعداد الباحثة، من نتائج التحليل الإحصائي SPSS، 2020م 
يتضح من جدول (12) أنَّ قيمة معامل الارتباط بين (الإيثار) و(الصورة الذهنية) تقدر بـ(0,220) بمستوى دلالة (0,024)، وهذا يعني أنَّه نوجد علاقة طردية ضعيفة بين (الإيثار) و(الصورة الذهنية)، أي أنَّه كلما زاد اهتمام العاملات في الجامعة بـ (الإيثار ) كلما أدى ذلك إلى تحسين الصورة الذهنية للجامعة. إذاً: توجد علاقة ذات دلالة إحصائية عند مستوى معنوية ج 0.05 بين الإينار والصورة الذهنية لجامعة أم درمان الإسلامية، و هذا يؤكد صحة الفرضية الأولى مما بعني قبولها. 2/ توجد علاقة ذات دلالة إحصائية عند مستوى معنوية 20.05 بين الكياسة لاى عضوات هيئة التدريس و الموظفات بجامعة أم درمان الإسلامية وتحسين الصورة الذهنية للجامعة. قامت الباحثة باستخدام معامل الارتباط بيرسون لمعرفة العلاقة بين المتغير المستقل (الكياسة) والمتغير التابع (الصورة الذهنية) وجاءت قيم معامل الارتباط للفرضية الثانية كما في جدول (13) جدول (13): يوضح العلاقة بين (الكياسة) و(الصورة الذهنية)

\begin{tabular}{|c|c|}
\hline 0,179 & قيمة معامل الارتباط (r) \\
\hline 0,067 & مستوى الدلالة \\
\hline غير دال (لا توجد علاقة) & القرار \\
\hline
\end{tabular}

* معامل الارتباط دال إحصائياً عند مستوى دلالة معنوية أقل من (0,05) المصدر: إعداد الباحثة، من نتائج التحليل الإحصائي SPSS، 2020م

يتضح من جدول (13) أنَّ قيمة معامل الارتباط بين (الكياسة) و(الصورة الذهنية) تقدر بـ(0,179) بمستوى دلالة (0,067)، و هذا يعني أنَّه لا توجد علاقة بين (الكياسة) و (الصورة الذهنية). إذاً: لا نوجد علاقة ذات دلالة إحصائية عند مستوى معنوية ج 0.05 بين الكياسة والصورة الذهنية لجامعة أم درمان الإسلامية، و هذا يؤكد عدم صحة الفرضية الثانية مما يعني عدم قبولها. 3/ توجد علاقة ذات دلالة إحصائية عند مسنوى معنوية ج 0.05 بين الروح الرياضية لاى عضو ات هيئة التدريس و الموظفات بجامعة أم درمان الإسلامية وتحسين الصورة الذهنية للجامعة. قامت الباحثة باستخدام معامل الارنباط بيرسون لمعرفة العلاقة بين المتغير المستقل (الروح الرياضية) و المتغير التابع (الصورة الذهنية) وجاءت قيم معامل الارنباط للفرضية الثالثة كما في جدول (14) جدول (14): يوضح العلاقة بين (الروح الرياضية) و(الصورة الأهية)

\begin{tabular}{|c|c|}
\hline 0,210 & قيمة معامل الارتباط (r) \\
\hline 0,032 & مستوى الدلالة \\
\hline دال (توجد علاقة طردية ضعيفة) & القرار \\
\hline
\end{tabular}

* معامل الارتباط دال إحصائياً عند مستوى دلالة معنوية أقلّ من (0,05) المصدر: إعداد الباحثة، من نتائج التحليل الإحصائي SPSS، 2020م 
يتضح من جدول (14) أنَّ قيمة معامل الارنباط بين (الروح الرياضية) و (الصورة الذهنية) تقدر بـ (0,210) بمسنوى دلالة (0,032)، و هذا يعني أنَّهَ توجد علاقة طردية ضعيفة بين (الروح الرياضية) و(الصورة الذهنية)، أي أنَّهَ كلما زاد اهتمام

العاملات في الجامعة بـ (الروح الرياضية) كلما أدى ذللك إلى تحسين الصورة الذهنية للجامعة. إذاً: توجد علاقة ذات دلالة إحصائية عند مستوى معنوية > 0.05 بين الروح الرياضية والصورة الذهنية لجامعة أم درمان الإسلامية، و هذا يؤكد صحة الفرضية الثالثة مما يعني قبولها.

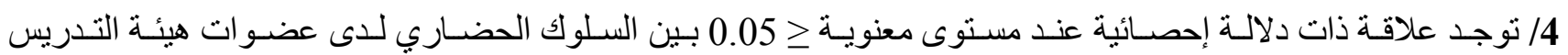
و الموظفات بجامعة أم درمان الإسلامية وتحسين الصورة الذهنية للجامعة. قامت الباحثة باستخدام معامل الارنباط بيرسون لمعرفة العلاقة بين المتغير المستقل (السلوك الحضاري) والمنتغير التابع (الصورة الذهنية) وجاءت قيم معامل الارتباط للفرضية الثالثة كما في الجدول (15). جدول (15): يوضح العلاقة بين (السلوك الحضاري) و(الصورة الأهنية)

\begin{tabular}{|c|c|}
\hline 0,305 & قيمة معامل الارتباط (r) \\
\hline 0,002 & مستوى الالالة \\
\hline دال (توجد علاقة طردية ضعيفة) & القرار \\
\hline
\end{tabular}

* معامل الارتباط دال إحصائياً عند مستوى دلالة معنوية أقل من (0,05) المصدر: إعداد الباحثة، من نتائج التحليل الإحصائي SPSS، 2020م

يتضح من جدول (15) أنَّ قيمة معامل الارتباط بين (السلوك الحضاري) و(الصورة الذهنية) تقدر بـ(0,305) بمسنوى دلالة (0,002)، و هذا يعني أنَّهَ نوجد علاقة طردية ضعيفة بين (السلوك الحضاري) و(الصورة الذهنية)، أي أنَّه كلما ز اد اهتمام العاملات بالجامعة بـ (السلوك الحضاري) كلما أدى ذلك إلى تحسين الصورة الذهنية لهنية للجامعة. إذاً: نوجد علاقة ذات دلالة إحصائية عند مستوى معنوية ج 0.05 بين السلوك الحضاري و الصورة الذهنية لجامعة أم درمان الإسلامية، وهذا يؤكد صحة الفرضية الر ابعة مما بعني قبولها.


بجامعة أم درمان الإسلامية وتحسين الصورة الذهنية للجامعة. قامت الباحثة باستخدام معامل الارتباط بيرسون لمعرفة العلاقة بين المتغير المستقل (وعي الضمير) والمتغير التابع (الصورة الذهنية) وجاءت قيم معامل الارنباط للفرضية الثالثة كما في الجدول (16).

جدول (16): يوضح العلاقة بين (وعي الضمير) و(الصورة الذهنية)

\begin{tabular}{|c|c|}
\hline 0,300 & قيمة معامل الارتباط (r) \\
\hline 0,002 & مستوى الدلالة \\
\hline دال (توجد علاقة طردية ضعيفة) & القرار \\
\hline
\end{tabular}

* معامل الارتباط دال إحصائياً عند مستوى دلالة معنوية أقل من (0,05) المصدر: إعداد الباحثة، من نتائج التحليل الإحصائي SPSS، 2020م 
يتضح من جدول (16) أنَّ قيمة معامل الارنباط بين (وعي الضمير) و(الصورة الذهنية) تقدر بـ(0,300) بمستوى دلالة (0,002)، و هذا يعني أنَّه توجد علاقة طردية ضعيفة بين (وعي الضمير) و(الصورة الذهنية)، أي أنَّه كلما زاد اهتمام العاملات بالجامعة بـ (وعي الضمير ) كلما أدى ذللك إلى تحسين الصورة الذهنية للجامعة. إذاً: توجد علاقة ذات دلالة إحصائية عند مستوى معنوية ج 0.05 بين وعي الضمير والصورة الذهنية لجامعة أم درمان الإسلامية، و هذا يؤكد صحة الفرضية الخامسة مما يعني قبولها. الفرضية الرئيسة الثانية:- توجد فروق ذات دلالة إحصائية عند مستوى معنوية > في فئه آراء عضوات هيئة التدريس والموظفات بجامعة أم درمان الإسلامية نحو سلوك المواطنة التنظيمية تعزى لمتغيرات (الوظيفة، ومدة الخدمة، والمؤهل

للإجابة على هذه الفرضية نم طرح عدد من الأسئلة الديموغر افية حول (الوظيفة، ومدة الخدمة، والمؤهل العلمي)، لعضو ات هيئة التدريس والموظفات بجامعة أم درمان الإسلامية، وتم إجر اء التحليل الإحصائي باستخدام تحليل التباين الأحادي (ONE WAY ANOVA)، وفيما يلي عرض للنتائج التي تم التوصل لها من خلال جدول (17). جدول (17): نتائج تحليل التباين الأحادي بشأن الفروق في درجة الاتجاه نحو سلوك المواطنة التظيمية

\begin{tabular}{|c|c|c|c|c|c|c|c|}
\hline الإحصائية & الدلالة & قيمة (F) & متوسط المربعات & الحرية & المربعات & مصدر التباين & أسم \\
\hline \multirow{3}{*}{ غير دال } & \multirow{3}{*}{0,758} & \multirow{3}{*}{0,393} & 0,039 & 3 & 0,118 & بين المجموعات & \multirow{3}{*}{ الوظيفة } \\
\hline & & & 0,1 & 101 & 10,08 & داخل المجموعات & \\
\hline & & & - & 104 & 10,2 & المجموع & \\
\hline \multirow{3}{*}{ غير دال } & \multirow{3}{*}{0,091} & \multirow{3}{*}{2,216} & 0,21 & 3 & 0,63 & بين المجموعات & \multirow{3}{*}{ مدة } \\
\hline & & & 0,095 & 101 & 9,568 & داخل المجموعات & \\
\hline & & & - & 104 & 10,2 & المجموع & \\
\hline \multirow{3}{*}{ غير دال } & \multirow{3}{*}{0,067} & \multirow{3}{*}{2,769} & 0,263 & 2 & 0,525 & بين المجموعات & \multirow{3}{*}{ العؤهل } \\
\hline & & & 0,095 & 102 & 9,673 & داخل المجموعات & \\
\hline & & & - & 104 & 10,2 & المجموع & \\
\hline
\end{tabular}

المصدر: إعداد الباحثّة، من نتائج التحليل الإحصائي SPSS، 2020م

يتضح من جدول (17) عدم وجود فروق ذات دلالة إحصائية عند مستوى معنوية ج 0.05 في اتجاهات عضوات هيئة التدريس و الموظفات بجامعة أم درمان الإسلامية مجمع الطالبات نحو سلوك المواطنة التظظيمية وفق متغيرات (الوظيفة، ومدة الخدمة، والمؤهل العلمي)، حيث بلغت قيمة F (0,393، 2,216، 2,769) على التوالي وهي قيم غبر دالة إحصائياً عند مستوى دلالة (0,05)، مما يدل على أنَّ (الوظيفة، ومدة الخدمة، و المؤهل العلمي) لا تؤثر في اتجاهات العاملات في جامعة أم درمان الإسلامية نحو توفر سلوك المو اطنة التنظيمية لديهن بأبعاده المختلفة أو عدم توفره، وذلك يعني عدم قبول الفرضية. 
الفرضية الرئيسة الثالثة: توجد فروق ذات دلالة إحصائية عند مستوى معنوية ج 0.05 في آراء عضوات هيئة التدريس و الموظفات بالجامعة نحو الصورة الذهنية للجامعة تعزى لمتغيرات (الوظيفة، ومدة الخدمة، والمؤهل العلمي). للإجابة على هذه الفرضية نم طرح عدد من الأسئلة الديموغرافية حول (الوظيفة، ومدة الخدمة، والمؤهل العلمي)، لعضوات هيئة التدريس و الموظفات بجامعة أم درمان الإسلامية، وتم إجر اء التحليل الإحصائي باستخدام تحليل التباين الأحادي

(ONE WAY ANOVA)، وفيما يلي عرض للنتائج التي نم التوصل لها في جدول (18).

جدول (18): نتائج تحليل التباين الأحادي بثأن الفروق في درجة الاتجاه نحو الصورة الذهنية

\begin{tabular}{|c|c|c|c|c|c|c|c|}
\hline الإحصائية & مستوى الدلالة & قيمة (F) & المربعات & الحرية & المربعات & مصدر التباين & أسم المتغير \\
\hline \multirow{3}{*}{ غير دال } & \multirow{3}{*}{0,423} & \multirow{3}{*}{0,943} & 0,519 & 3 & 1,557 & بين المجموعات & \multirow{3}{*}{ الوظيفة } \\
\hline & & & 0,55 & 101 & 55,58 & داخل المجموعات & \\
\hline & & & - & 104 & 57,14 & المجموع & \\
\hline \multirow{3}{*}{ غير دال } & \multirow{3}{*}{0,796} & \multirow{3}{*}{0,341} & 0,191 & 3 & 0,573 & بين المجموعات & \multirow{3}{*}{ مدة الخدمة } \\
\hline & & & 0,560 & 101 & 56,57 & داخل المجموعات & \\
\hline & & & - & 104 & 57,14 & المجموع & \\
\hline \multirow{3}{*}{ دال } & \multirow{3}{*}{0,041} & \multirow{3}{*}{3,295} & 1,734 & 2 & 3,468 & بين المجموعات & \multirow{3}{*}{ العؤهل } \\
\hline & & & 0,526 & 102 & 53,67 & داخل المجموعات & \\
\hline & & & - & 104 & 57,14 & المجموع & \\
\hline
\end{tabular}

المصدر: إعداد الباحثة، من نتائج التحليل الإحصائي SPSS، 2020م

يتضح من جدول (18) عدم وجود فروق ذات دلالة إحصائية عند مستوى معنوية ج205 في اتجاهات عضوات هيئة التدريس و الموظفات بجامعة أم درمان الإسلامية مجمع الطالبات نحو الصورة الذهنية وفق متغيرات (الوظيفة، ومدة الخدمة)، حيث بلغت قيمة F (0,943، 0,341) على التو الي وهي قيم غير دالة إحصائياً عند مستوى دلالة (0,05)، مما بدل على أنَّ (الوظيفة، ومدة الخدمة) لا تؤثر في اتجاهات العاملات في جامعة أم درمان الإسلامية نحو توفر الصورة الذهنية.

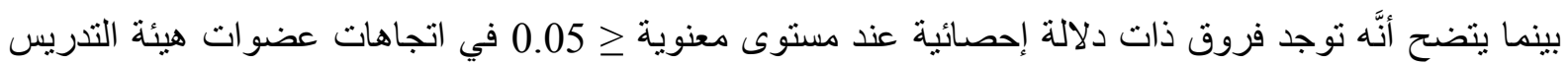
و الموظفات بجامعة أم درمان الإسلامية نحو الصورة الذهنية للجامعة تعزى لمتغير المؤهل العلمي حيث بلغت قيم F,295 و هي دالة إحصائياً عند مستوى (0,05)، و هذه النتيجة تثير إلى أنَّ المؤهل العلمي له أهمية نحو الصورة الذهنية للجامعة لدى عينة الدر اسة. وذلك يعني عدم قبول الفرضية إلا فيما ينعلق بالجزء الخاص بمتغير المؤهل العلمي فقط. النتائج والتوصيات:-

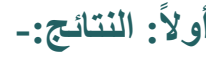

كان الهدف من هذه الدر اسـة هو الوقوف على واقع سلوك المواطنة التنظيميـة وعلاقتـه بالصـورة الذهنيـة لجامعـة أم درمان الإسلامية، و استتاداً على نتائج التحليل الإحصائي، واختبار فرضيات الدراسة نوصلت الباحثة إلى النتائج التالية:- 
1- أظهرت النتائج أنَّ درجة الإيثار لدى عينة الدر اسة بالجامعة كانت مرتفعـة، حيث بلغ الوسط الحسابي لبُعد الإيثار(4,70) وبانحر اف معياري (0,335).

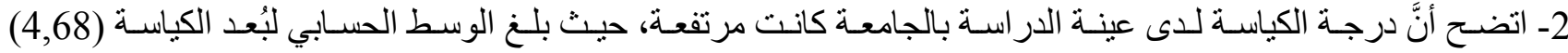
وبانحر اف معياري (0,353). 3- تبين أنَّ درجة الروح الرياضية لاى عينة الدر اسة بالجامعة كانت مرتفعة، حيث بلغ الوسط الحسابي لبُعد الروح الرياضية. (4,35) وبانحر اف معياري (0,488)

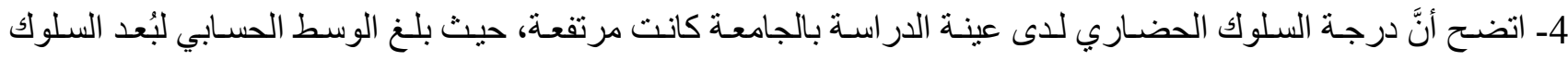
الحضاري(4,57) وبانحر اف معياري (0,408). 5- تبين أنَّ درجة و عي الضمير (الالتز ام العام) لدى عينة الدر اسة بالجامعة كانت مرتفعة، حيث بلغ الوسط الحسابي لبُعد وعي الضمير (الالتزام العام)(4,66) وبانحر اف معياري (0,386)

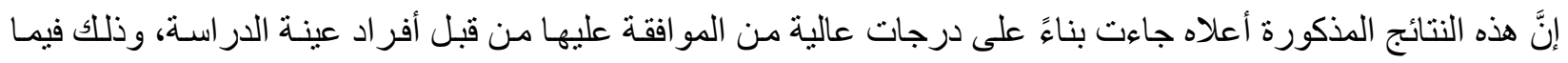
يتعلق بسلوكيات إيجابية كثيرة مثل مساعد الزملاء الحاليين و الجدد، وكذلك التعاون مـع الرؤسـاء، وتقديم المصلح العامـة على دهى المصلحة الثخصية وغير ها. وبالتالي فهي تتفق مع الجانب النظري في الأدبيات الذي يشير إلى أنَّ تو افر مثل هذه السلوكيات مهم لنجـاح المنظمـة وتحقيق الفعاليـة فيها، وبالتـالي تحسين سـعتها وهي متفقة مـع مـا ورد في نتـائج در اسـة (عبد المجيد

$$
\text { و العوفي،2016م)، ودر اسة (مناصرية وبن ختو، 2015م). }
$$

6- اتضح أنَّ درجة الوعي بالصورة الذهنية لادى عينة الدر اسة بالجامعة كانت مرتفعة، حيث بلغ الوسط الحسـابي لبُعد الصورة الذهنية(3,69) وبانحر اف معياري (0,741). وذللك لأنَّ معظم العبار ات جاءت بالمو افقة عليها. و هذا يتفق مع در اسة (معدري، 2015م) التي تشير إلى أنَّ أحد أنواع الصـورة الذهنيـة تتمثنل فيمـا تر اه المؤسسـة عن نفسها مـن خـلال موظفيها أو من خـلال

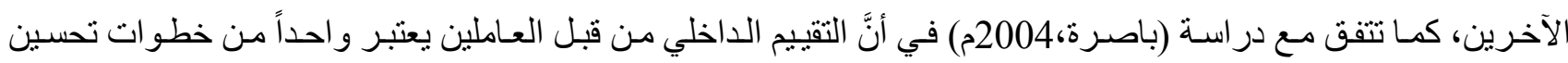
الصورة الذهنية. 7- أظهرت نتائج الدر اسـة عن وجود علاقة ذات دلالـة إحصـائية عند مستوى معنويـة أقل من (0,05) بين الإيثنار ، والروح الرياضية، و السلوك الحضاري، ووعي الضمير وبين الصورة الذهنية. 8ـ كما توصلت نتائج الدر اسة إلى عدم وجود علاقة ذات دلالة إحصائية عند مستوى معنوية أقل من (0,05) بين الكياسـة وبين

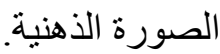
بالنسبة للنتيجتين السابقتين، فإنَّ عدم توفر الكياسة أو المجاملة لا يعني عدم توفر سلوك المواطنة التنظيمية، إلا أنَّ ذلك قد ينبه المؤسسة المبحوثة (الجامعة) إلى العمل على تعزيز هذا السلوك و الحث عليه كما أوصت الكثير من الدراسات. لكن نظل العلاقة بين سلوك المواطنة التنظيمية والصورة الذهنية موجودة وقوية من خلال علاقة الارنباط التي أظهرتها بقية الأبعاد، و هي بذلك تتفق من أدبيات الدر اسة مثل در اسة (المصري، مـ 2015م). 9ـ كثفت نتائج الدر اسة عن عدم وجود فروق ذات دلالة إحصائية بين آر اء عضوات هيئة التدريس وموظفات جامعة أم درمـان الإسلامية نحو سلوك المواطنة التنظيمية قد تعزى لمتغير ات: (الوظيفة، ومدة الخدمة، المؤهل العلمي). 
10- بينت نتائج التحليل الإحصـائي عن عدم وجود فروق ذات دلالة إحصـائية بين آر اء عضوات هيئة التدريس وموظفات

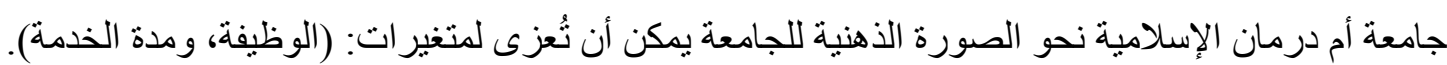

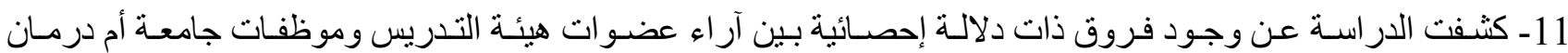
الإسلامية نحو الصورة الذهنية للجامعة تعزى لمتغير المؤهل العلمي. أيضاً النتائج الثلاث الأخيرة تؤكد ما جاءت به الدر اسات عن دور المتغير ات الثخصية (الديمو غر افية) في سلوك المواطنة باعتبار ها من المحددات التي تؤثر في هذا السلوك، وذللك بالاتفاق مع العديد من الدر اسات مثل (در اسة نادر،2012م). ثُانياً: التوصيات:-

استناداً إلى ما أثنارت إليه نتائج الدر اسة من توفر أبعاد سلوك المو اطنة التنظيمية بمعدل مرتفع لاى عينة الدر اسة، فإنَّهـ يتم التوصية بالآتي:-

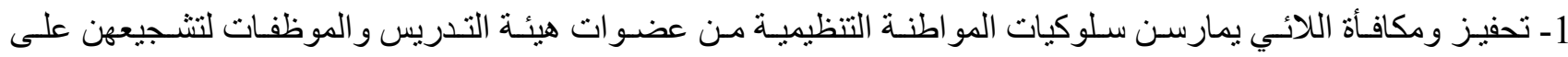
الاستمر ار فيه ونقله للزميلات في محيط العمل. 2- تشجيع عضو ات هيئة التدريس و الموظفات على ممارسة اللطف والمجاملة ( الكياسة) بدرجة أكبر، وكذلك نشر ثقافة العمل الطوعي التعاوني، وذلك من خـلال عمل لقاءات وندوات توضـح دور التعاون و اللطف في تحسين الصورة الذهنية للجامعـة داخلياً ومع المحيط الخارجي. 3- جعل سلوك المو اطنة التنظيمية واحداً من المعايير التي تستخدم في تقييم الأداء. 4- تبني إدارة الجودة و التقويم بالجامعة نشر مثل هذه المفاهيم الإيجابية وسط الأستاذات و الموظفات للارتقاء بالجامعـة وتحسين سمعتها وصورتها الذهنية الأمر الذي يكسبها ميزة تنافسية. 5- وضع استر اتيجية لرسم الصورة الذهنية المستهدفة للجامعة و العمل على تتفيذها وتحسينها باستمر ار. 7- إجر اء المزيد من الدر اسات حول الكثير من المتغير ات التي تسـاعد على اكتسـاب وممارسـة سلوك المواطنة التنظيمية من قبل الأستاذات و الموظفات بالجامعة، مثل المناخ التنظيمي، القيادة الخادمة، وفرق العمل و غير ها.

1- أبو سمعان، محمد ناصر راشد(2015)). محددات العدالة التنظبية وعلاقتها بسلوك المواطنة التنظبية من وجهة نظر الضباط في جهاز الثرطة بقطاع غزة، (رسالة ماجستير غير منشورة في إدارة الأعمال)، كلية التجارة، الجامعة

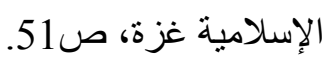

2- أبو عجوة، حسام (2021م). دور التسويق الفيروسي في تحسين الصورة الذهنية لشركة الاتصالات الفلسطينية


3- باصرة، محمد بن محسن (2004م). دور العلاقات العامة في بناء الصورة الذهنية بالمؤسسات الخيرية، ورقة عمل مقدمة في اللقاء السنوي الخامس للجهات الخيرية بالمنطقة الثرقية، المملكة العربية السعودية، 14 ديسمبر. 
4- بن الثيخ، هاجر(2017م). أثر الإعلان في تحسين الصورة الذهنية للمؤسسة الذدمية: دراسة حالة مؤسسة اتصالات الجزائر للهاتف النقال موبيليب، (مذكرة مقدمة لاستكمال منطلبات شهادة الماستر)، قسم العلوم التجارية، كلية العلوم

$$
\text { الاقتصادية و التجارية و علوم التسيير، جامعة قاصدي مرباح، الجز ائر، ص23. }
$$

5- - حسنى، محمد شميس (2021م). الدور الوسيط للالتزام التنظيمي في العلاقة بين الصمت التنظيمي وأبعاد سلوك المواطنة التنظيمية بالمؤسسات العامة: دراسة ميدانية على شركات قطاع الدوية الحكومي بمحافظة القاهرة، مجلة

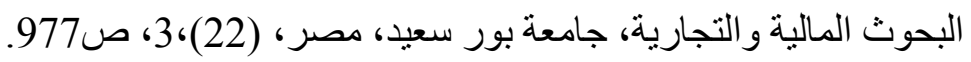
6- دعنا، صباح جوهر (2017م). سلوك المواطنة التنظبية في مديريات التربية والتعليم شمال الخليل ووسطها، (رسالة ماجستير غير منشورة في إدارة الأعمال)، كلية الدراسات العليا، جامعة الخليل، فلسطين، ص ص صل 20-22. 7- رسول، عبد الحكيم مصطفى (2016). مستوى سلوك المو اطنة التنظيمية لاى أعضاء الهيئة التدريسية في كليات و أقسام التربية الرياضية في جامعات صلاح الدين وسوران وكوية، مجلة دراسات وبحوث التربية الرياضية، 46،

8- زين العابدين، محمد جياد (2019م). العلاقات العامة الالكترونية وعلاقتها ببناء صورة المؤسسة الجامعية، مجلة


9- سعدون، سمية؛ وغيات، بوفلجة؛ وبزايد، نجاة (2017م). المواطنة التنظيمية وعلاقتها بالإبداع الإداري: دراسة ميدانية بمؤسسة سوناطر اك (و هران)، مجلة آفاق فكرية، كلية العلوم الإنسانية والاجتماعية، جامعة جيلالي ليابساسيدي بلعباس، الجزائر، (3) 7، 182 - 184.

10- سعيد، محمد عودة عبد الله (2017م). الاغتراب الوظيفي وعلاقته بسلوك المواطنة التنظيبية لدى العاملين في وزارة الأوقاف والثئون الدينية، (رسالة ماجستير غير منشورة)، أكاديمية الإدارة والسياسة للار اسات العليا، غزة، فلسطين،

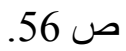

11-ظاظا، يمان حورية (2017م). دراسة العوامل المحددة لسلوك المواطنة التنظيمية لدى العاملين في منظمة الهلال الأحمر العربي السوري-فرع ريفي دمشق، (رسالة ماجستير غير منشورة في إدارة الأعمال)، الجامعة الافتراضية السورية، دمثق، ص26.

12- عبد الخير، فرح يس فرح؛ وبدوي، مأمون يس؛ وعبد الله، بثينة آدم (2017م). أثر الثقافة التنظيمية على إدارة الصورة الذهنية بالوزارات الحكومية: وزارة التخطيط العمراني والمرافق العامة بولاية القضارف نموذجاً، المجلة الدولية للعلوم الإنسانية والاجتماعية، 1، 2.

13- العادلي، مرزوق عبد الحكم (2013م). الصورة الذهنية للمؤسسة العسكرية لدى الجمهور المصري بعد ثورة 30 يونيو، مجلة كلية الآداب، جامعة سو هاج، مصر، 408، 35.

14- عبد الفتاح، فادي عبد المنعم أحمد (2011م). دور التسويق الاككتروني في تحسين الصورة الذهنية للخدمات الصحية: دراسة حالة من وجهة نظر عملاء الثركة الأردنية الفرنسية للتأمين، (رسالة ماجستير غير منشورة في إدارة الأعمال)، كلية الأعمال، جامعة الثرق الأوسط، الأردن، صاهُه 
15- عبد المجيد، أشرف عبد التواب؛ والعوفي، زهور سمران مرزوق (2016م)، العلاقة بين العدالة التنظيمية وسلوك المو اطنة التنظيمية لدى المشرفات التربويات بمدينة تبوك، مجلة دراسات عربية في التربية وعلم النفس،80، 335-

16- العسيري، عبد الله علي (2018م). تطوير المهارات المتعلقة بالإعلام الجديد وتغيير الصورة الذهنية لتحقيق الأهداف

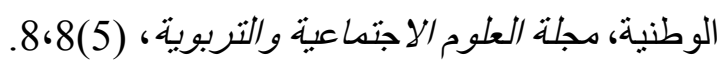

17- عطية، غادة عادل؛ والمقدم، مصطفى صلاح (2018م). اللغة الدافعة كتغير وسيط بين القيادة الخادمة وكل من سلوك المو اطنة التنظيمية والتز ام التابعين نحو القائد: بالتطبيق على شركات تجارة تجزئة الأغذية بالإسكندرية، مجلة

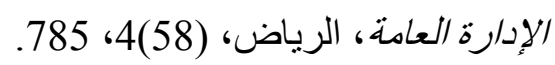
18ـ القبلان، نجاح قبلان (2016م). الصور الذهنية لمهنة المكتبات و المؤسسات المعلوماتية ومستقبلها، مجلة مؤسسة قطر الأكاديبية، نقلا عن:-

Q Science connect, http//dx.doi.org/10.5339/connect.2016.slaagc. 19-محمد، و ائل عبد الله (2017م). دور العلاقات العامة في تحسين الصورة الذهنية لديوان الضرائب الاتحادي بولاية الخرطوم، (بحث غير منشور مقدم لنيل درجة الماجستير في الإعلام الأمني)، كلية الدراسات العليا والبحث العلمي، جامعة الرباط الوطني، السودان، ص 62. 20-محي الدين، نيتثمان عثمان؛ ومحمود، فريدون محمد (2017م). دور أخلاقيات الأعمال في تحسين الصورة الذهنية للمنظمات الخدمية الربحية: دراسة استطلاعية لآراء عينة من العاملين في منظمات الأعمال العاملة في مدينة السليمانية. إقليم كردستان العراق، مجلة جامعة التنمبية البثرية، (3)3، 311.

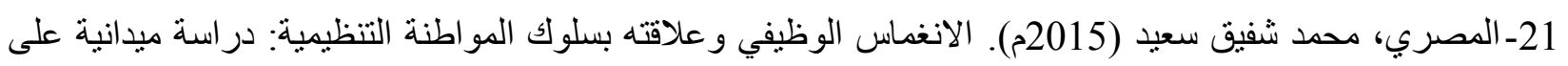
المستشفيات الحكومية في قطاع غزة، (رسالة ماجستير غير منشورة في إدارة الأعمال)، كلية الاقتصاد و العلوم

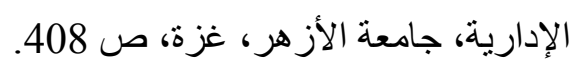
22-معمري، أمينة (2015م). دور الاتصال الداخلي في تشكيل الصورة الذهنبة للمؤسسة الجامعية: دراسة ميدانية برئاسة جامعة العربي بن مهيبي أم البواقي، (مذكرة مكملة لنيل شهادة الماستر في علوم الإعلام والاتصال)، قسم العلوم الإنسانية، كلية العلوم الاجتماعية والإنسانية، جامعة العري بن مهيدي أم البو اقي، الجزائر، ص22. 23- مناصرية، رشيد؛ وبن ختو، فريد (2015م). سلوك المو اطنة التنظيمية و أهميته في تحسين أداء العاملين: دراسة حالة

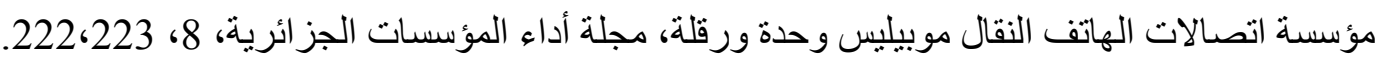
24-شهري، مينا سليمان(2019م). سلوك المو اطنة التنظيمية لدى أعضاء هيئة التدريس في الجامعات الحكومية الجزائرية

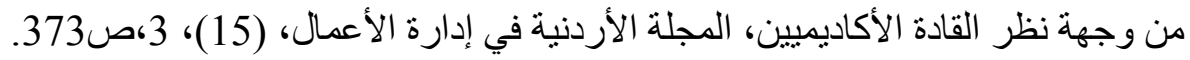
25-نادر، غنوة محمد (2012م). أثر الضنوط الوظيفية على المواطنة التنظبية: دراسة مسحبة على العاملين في المشافي العامة للساحل السوري، (رسالة ماجستير غير منشورة في إدارة الأعمال، كلية الاقتصاد، جامعة نشرين، ص 
26- النوافلة، يزن اكرم ( 2020م). الدور الاتصالي للعلاقات العامة في تشكيل الصورة الذهنية لدى الصبادلة: شركة الحكمة الأردنية للأدوية أنموذجاً، (رسالة ماجستير غير منشورة في إدارة الإعلام والعلاقات العامة، قسم الإعلام

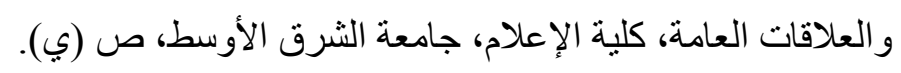

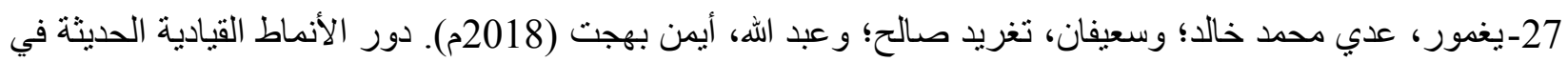

تعزيز سلوك المواطنة التنظيمية لاى الموظفين العاملين في البنوك الأردنية، المجلة الأردنبة في إدارة الأعدال،

28-حامد، سمية علي (سبتمبر/2019م). مقابلة شخصية، نائب مدير الإدارة العامة للموارد البشرية. جامعة أم درمان

$$
\text { الإسلامية. مجمع الطالبات. أم درمان. }
$$

29- بخيت، هاجر علي محمد (مديرة مجمع الطالبات جامعة أم درمان الإسلامية). (أكتوبر،2019م ). لقاء مدير الجامعة

$$
\text { بأسرة مجمع الطالبات. أم درمان الثورة. }
$$

\section{ثانياً: المراجع الأجنبية:- - ت}

1- Acaray, Ali \& Akturan, Abdulkadir (2015). The relationship between organizational citizenship behavior and organizational silence, paper introduced in $11^{\text {th }}$ international strategy management conference, published by Elsevier LTD. Procedia- Social and Behavioural Sciences ,207.

2- Chien, Min-Huei (2019), A study to improve organizational citizenship behaviors, developed at and hosted by the college of information sciences and te chnology, The Pennsylvania state university, teseer ${ }^{\mathrm{x}}$. ist.psu. edu, 1 .

3- Hatami, Khaidan; \& Esmaeili, Mohammad Reza;\& Sajadi, Sayed Hamid (2016). Predict organizational citizenship behavior of the staff based on the factors of the job satisfaction, Turkish journal of sport and exercise, faculty of sports sciences, Selcuk university,(18)2,97.

4- Vandewaa, Elizabeth; \& Turnipseed, David.L (2012). Emotional intelligence and organizational of university professors, The international journal of interdisciplinary social sciences,(6)7,2.

5- Velickovska, Ivana (2017). Organizational citizenship behavior - Definition, Determinations, and Effects, journal of engineering management, American society of engineering management, (1) 3,40 . 


\section{الموضوع: صحيفة استبيان}

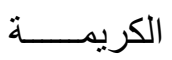
سعادة الأخت

السلام عليكم ورحمة الله وبركاته

أحيط سعادتكِ بأنَّي أقوم بعمل در اسة بعنوان: و اقع سلوك المواطنة التنظيمية و علاقته بالصورة الذهنية للجامعات السودانية، بالتطبيق على عضوات هيئة التدريس و الموظفات بجامعة أم درمان الإسلامية (مجمع الطالبات)، علماً بأنّ إكمال هذه الدر اسة ونجاحها يتوقف على كريم استجابتلك بالتكرم بإعطاء إجاباتلك من خلال مله الاستبيان المرفق.

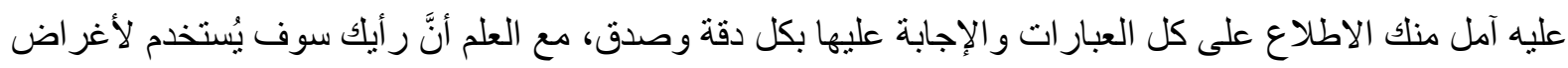

$$
\text { البحث العلمي فقط، وسيكون موضع السرية. }
$$

الرجاء وضع علامة ( ل ) أمام الإجابة التي تختارينها.

ولكي مني خالص الثكر و التقدير

د/ حنان عثمان عمسيب محمد

أستاذ مساعد - قسم إدارة الأعمال

أولاً: البيانات الشخصية:-

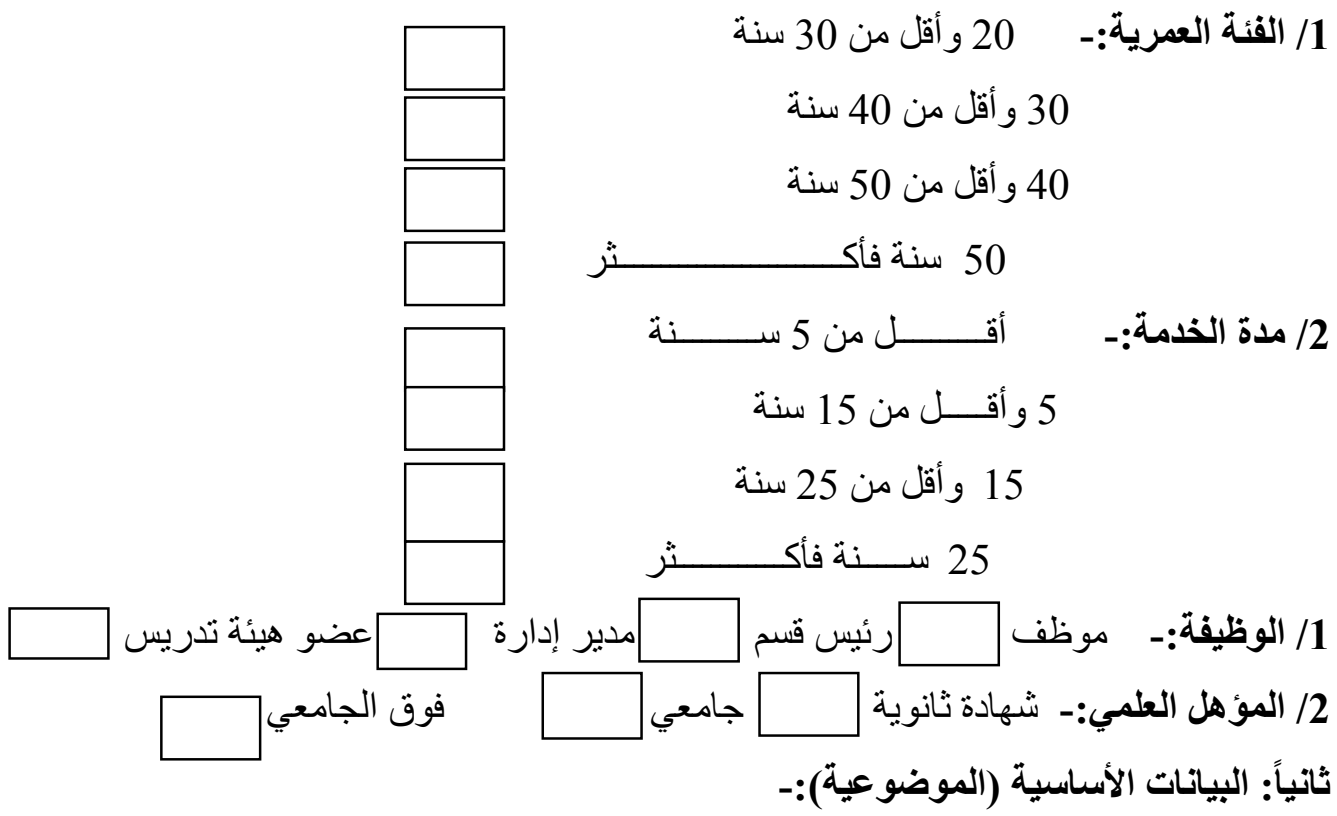

سلوك المواطنة التظيمية:- عبارة عن سلوك وظيفي يؤديه الفرد طواعية ويتعدى حدود الواجبات الوظيفية المحددة له، كما أنه لا يتم مكافأته عليه، وذلك من أجل تحقيق أهداف المنظمة ومساعدة العاملين والتعامل معهم.

\begin{tabular}{|c|c|c|c|c|c|c|}
\hline لا أوافق & $\begin{array}{c}\text { أو افق } \\
\text { أل }\end{array}$ & رأي & أوافق & أوافق & 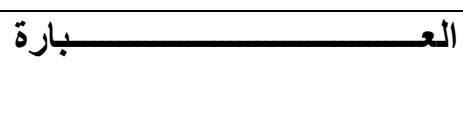 & $ت$ \\
\hline
\end{tabular}


المجلة الدولية لنشر البحوث والدراسات

International Journal of Research and Studies Publishing
تألخلد الثالث - الإصدار الثامن والعشرون تأريخ الإصدار: 20 فبراير 2022 م

ISSN: 2709-7064

| 1 2 3 4 | 5 بُعد الكياسة(اللطف): المساهمة في عدم حدوث المشكلات لضمان الاستقرار والهاوء للزملاء في العمل.

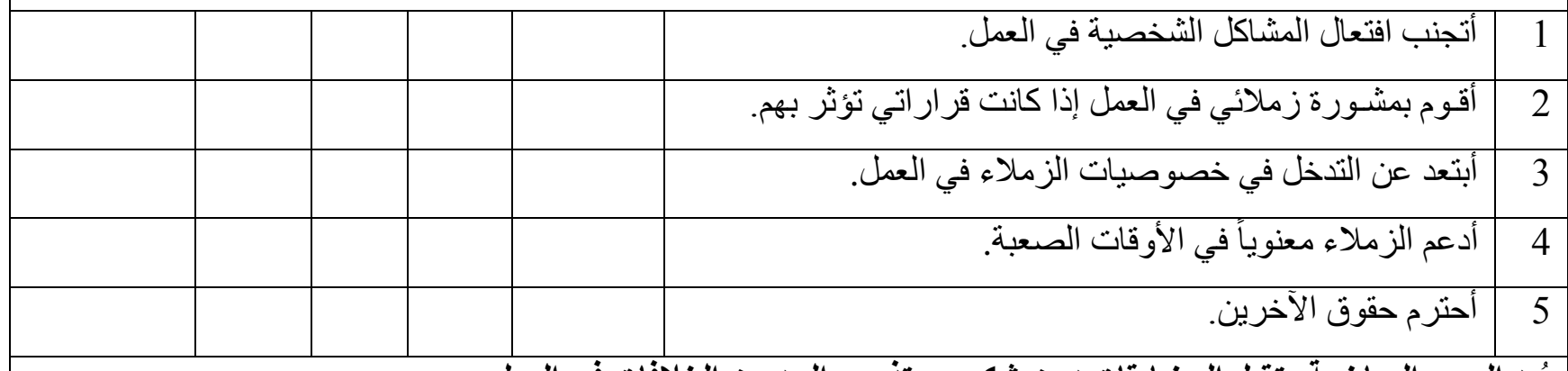

بُعد الروح الرياضية: تقبل المضايقات دون شكوى وتذمر والحد من الخلافات في العمل.

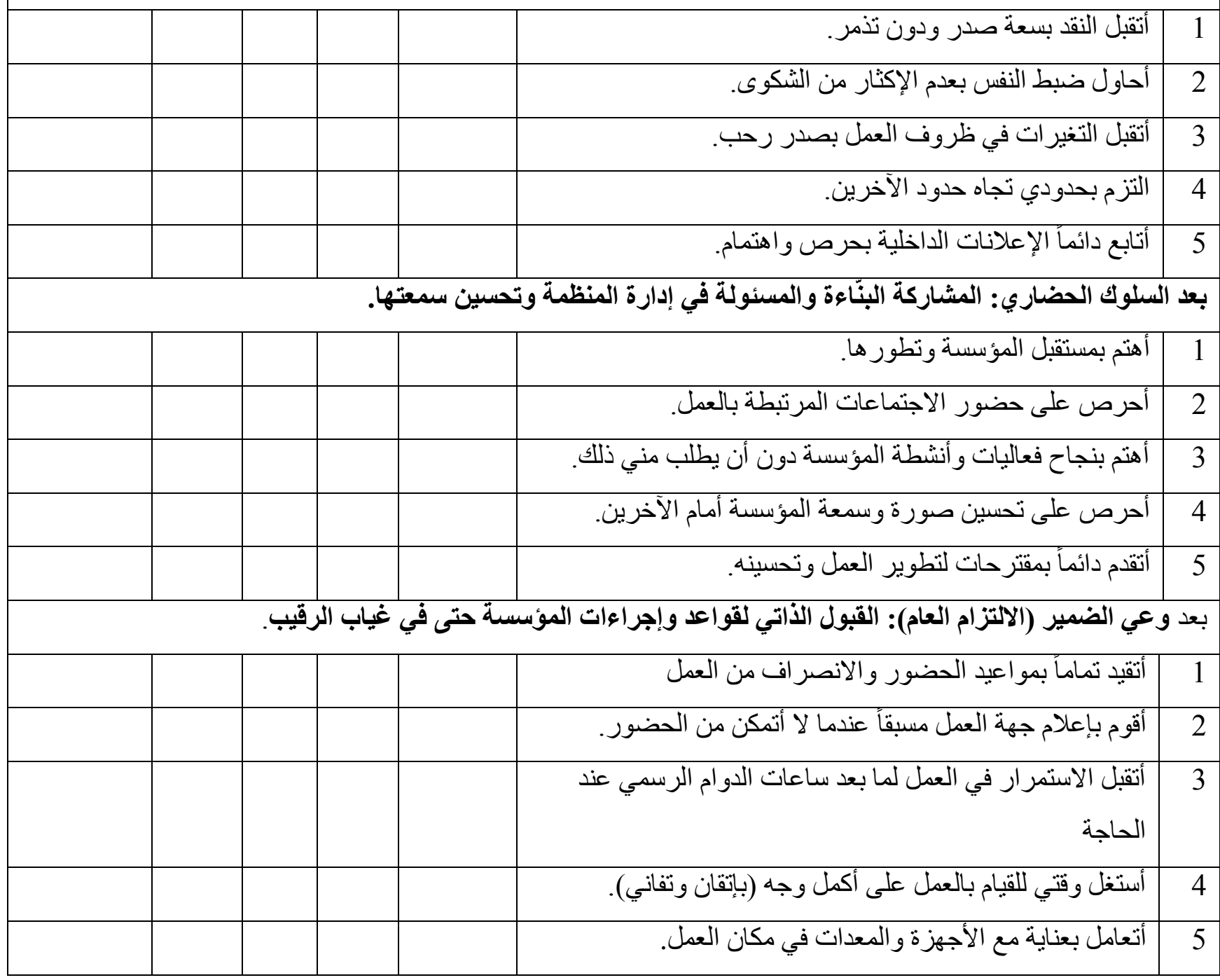


الهجلة الدولية لنشر البحوث والدراسات

International Journal of Research and Studies Publishing

ISSN: 2709-7064
الهجلد الثالث - الإصدار الثامن والعشرون تأريخ الإصدار: 20 فبراير 2022 م



ولكم خالص الثكر و التقدير

Doi: $\underline{\text { doi.org/10.52133/ijrsp.v3.28.2 }}$ 